\title{
El complejo psicotrópico en Solcor 3 (San Pedro de Atacama)
}

\author{
Agustín Llagostera $^{1}$, Manuel C. Torres $^{2}$ y M. Antonietta Costa ${ }^{1}$
}

San Pedro de Atacama es reconocido en el ámbito de la arqueología por el alto número de tabletas y tubos que, por asociación etnográfica, sabemos que se relacionan con la esfera chamánica. En los registros de Le Paige hemos contabilizado 522 tabletas, en una muestra de 20 cementerios con un total de 2574 tumbas; esto representa un promedio de $20 \%$ de sepulturas cuyos ocupantes aparecerían comprometidos con el uso de esta parafernalia. La cifra obtenida nos da licencia para calificar a los atacameños como un grupo marcadamente chamanista, que lograba el éxtasis sirviéndose de un equipo bien definido y utilizando drogas que eran inhaladas por vía nasal.

Las investigaciones sobre tabletas para alucinógenos se inician con el arqueólogo alemán Max Uhle, quien escribió cuatro artículos sobre la función, origen y cronología de las tabletas y de los tubos. El primero de sus trabajos sobre este tema está centrado en un tubo inhalador procedente del sitio de Tiwanaku. Aunque este trabajo no se refiere específicamente al norte de Chile, debe ser mencionado porque sirve de base a sus subsecuentes estudios (Uhle 1898). Uhle, en ese trabajo establece clara diferencia entre la inhalación del tabaco y la del llamado yopo, un polvo obtenido de las semillas de la leguminosa conocida técnicamente como Anadenanthera. En su trabajo cita cronistas del siglo XVI, como Pedro Mártir de Angleria, quienes indican que la intoxicación producida por la ingestión de estos polvos es mayor que aquella producida por el tabaco. Uhle piensa, además, que la inhalación de tabaco es más antigua que la de los polvos de la Anadenanthera (Uhle 1898: 167, 174).

En el XVII Congreso Internacional de Americanistas (Buenos Aires 1910), Uhle hizo una presentación sobre las relaciones prehispánicas entre Perú y Argentina (Uhle 1912: 533). El autor sostiene que

1 Instituto de Investigaciones Arqueológicas de la Universidad del Norte, San Pedro de Atacama, CHILE.

2 Universidad Internacional de La Florida, ESTADOS UNIDOS. las tabletas y los tubos fueron utilizados en la inhalación de polvos psicoactivos, encauzando ya en la interpretación correcta, la controvertida función de estos objetos. Arqueólogos argentinos como Juan B. Ambrosetti (1899: 42-45) y Robert Lehmann-Nitsche (1902: 10-11) sugerían que las tabletas eran para colocar ofrendas, y que los tubos pudieran haber sido usados como escarificadores. Uhle, al proponer la función inhaladora de los tubos y tabletas, cita extensa evidencia del uso de similares implementos entre grupos nativos del Amazonas. En su trabajo ilustra dos tabletas procedentes de Tiwanaku, que serían las tabletas más antiguas encontradas hasta esos momentos (Uhle 1912: 531, Figs. 15-16) y en el mismo trabajo manifiesta su opinión de que el uso de las tabletas y de los tubos fue introducido en el norte de Chile y noroeste de Argentina desde el altiplano boliviano.

El próximo escrito de Uhle (1913) sobre este tema consiste en un análisis de 27 tabletas procedentes de Chiu Chiu, norte de Chile. Este fue, básicamente, un estudio comparativo en el que el autor identificó motivos paralelos y repeticiones de temas entre las tabletas de ese sitio y otras, de diferentes zonas. Dos años más tarde, Uhle (1915) publica un artículo en el que propone una seriación temporal de los tubos inhaladores del norte de Chile.

Otro investigador de principios de siglo que se interesó por la función de tabletas y tubos fue el arqueólogo sueco Eric von Rosen. Una tableta y cuatro tubos procedentes del norte de Chile y del noroeste de Argentina son reproducidos en su recuento de la Expedición Sueca Chaco-Cordillerana de 19011902 (Ambrosetti 1907-08, vol. 2: Fig. 271; Von Rosen 1924: Figs. 68-72). Eric von Rosen fue el primero en notar la asociación de las cucharillas o espátulas, con los tubos y las tabletas. Otro estudioso que prestó atención a los objetos psicotrópicos del norte de Chile fue Montell (1926), quien discute varias tabletas procedentes del Loa Medio. Por el mismo tiempo, Looser (1926) reseña varias tabletas pertenecientes a la colección del Museo Nacional de Santiago. 
Con estos trabajos se estableció claramente la función de la parafernalia inhalatoria. La próxima fase de los estudios se concentra en cuestiones de origen y desarrollo cronológico. Uhle (1912) abordó estos temas cuando postuló un origen altiplánico para las tabletas. Oyarzún (1931: 75), en un breve artículo en el que reproduce 10 tabletas y cuatro tubos, también señala a Tiwanaku como el centro de origen de estos implementos. Oyarzún llega a estas conclusiones, basándose en las similitudes iconográficas y estilísticas entre las tabletas chilenas y las de procedencia altiplánica.

El postulado de que las tabletas tiwanakotas fueran las más antiguas fue desacreditado por dos trabajos de Bird (1943, 1948). Una tableta encontrada por este autor (1943) en el sitio Quiani puede haber estado asociada con material precerámico, aunque el sector donde fue encontrada había sido saqueado, y las asociaciones de esta tableta no pudieron establecerse con seguridad (Bird 1943: 248, Fig. 20a, b). En un sitio en la misma área, conocido como Playa de los Gringos, Bird (1943: 226, Fig. 13a, d, e) encontró una tableta y un tubo dentro de una bolsa en un contexto precerámico. Otras tabletas procedentes de contextos precerámicos o cerámico tempranos han sido reportadas en la costa peruana por Bird (1948) y por Engel (1963).

Latcham (1938), en su importante trabajo sobre las culturas arqueológicas del Desierto de Atacama, incluye un inventario de las 204 tabletas del norte de Chile que él conocía hasta ese momento. El autor propone una clasificación de las tabletas y sugiere que aquellas que presentan un panel abanicado pertenecen a un período de fuerte influencia tiwanakota (Latcham 1938: 133).

Núñez ha escrito varios artículos que tratan sobre este tema; en uno de ellos (1963) elabora una clasificación de las tabletas del norte de Chile. Le Paige tuvo gran interés en las tabletas y se preocupó de ellas en forma extensa (Le Paige 1963, 1964, 1965). Más recientemente Thomas y Benavente (1984, 1985) se han ocupado de sistematizar la correspondencia entre los elementos cerámicos y las tabletas del área de San Pedro de Atacama. Uno de nosotros (Torres 1986, 1987) ha considerado las tabletas de San Pedro de Atacama dentro de un análisis iconográfico de tabletas sudamericanas, haciendo algunos planteamientos sobre distribución y rutas de difusión.
Hasta ahora, sólo se han publicado dos trabajos que han intentado penetrar en esta problemática más allá de la mera descripción de las tabletas. Barón (1984), a través de un análisis de 202 cráneos asociados a elementos del complejo alucinógeno, llega a las siguientes conclusiones: 1) es la población adulta, especialmente la masculina, la que utilizaba estos elementos con mayor frecuencia $(77 \%$ hombres y $21 \%$ mujeres); 2) aquellas tabletas sin adornos harían pensar en un uso de la droga no ritual y quizás no muy común, y 3) los individuos con tabletas y además un rico ajuar, probablemente eran los encargados de ritos y ceremonias. Por su parte, Thomas y Benavente (1984) centran su trabajo en la elaboración de una tipología de tabletas, pero al final sugieren que, a través de las imágenes, sería posible extraer información antropológica en relación a diversos aspectos socioculturales de los atacameños. Así, piensan que las tabletas decoradas con personajes típicos de la Puerta del Sol de Tiwanaku pueden suministrar datos sobre la estructura social y religiosa; las tabletas con más de un personaje podrían tener relación con organizaciones duales y tríadas; las tabletas con representaciones de animales se podrían vincular a prácticas rituales propias de la religión chamánica, y otras, a los rituales (sacrificios humanos y cabezas-trofeo).

Nosotros, a través de información de primera mano obtenida de nuestras excavaciones, hemos querido profundizar en la temática chamanística de San Pedro de Atacama. Solcor 3, cementerio arqueológico ubicado en los deslindes del ayllu del mismo nombre, nos ha entregado una valiosa documentación propicia para abordar el tema desde una perspectiva antropológica. Solcor 3 presenta hasta ahora un $32 \%$ de tumbas con tabletas, porcentaje que sólo es superado por los cementerios de Coyo Oriente (38\%) y Quitor 6 (34\%); este dato es ya elocuente y favorable antecedente en la selección de este sitio para el objetivo propuesto.

Nuestro problema básico estará orientado a determinar quiénes eran las personas que en sus tumbas estaban asociadas con tabletas. Barón (1984), ya decíamos, las identificó preferentemente como varones adultos y muy pocos niños. El disponer de esqueletos completos nos permitirá chequear esa información y llegar a definir con más elementos de juicio, un patrón antropofísico para estas personas, considerando sexo, edad y deformación craneana. Asimismo, el contar con los correspondientes contextos controlados hará posible precisar un patrón 
de cultura mobiliar asociado al grupo de portadores de tabletas.

Indudablemente, los patrones antropofísicos y contextuales cobrarán significado en la medida que se les compare con los del resto de la población; si la comparación no señala diferencias significativas, se podrá pensar que el acceso a las drogas psicotrópicas no era restringido, suponiendo entonces, una participación colectiva; si los patrones son distintos, estaríamos frente a un grupo socialmente diferenciado que usufructuaba del chamanismo para mantener un determinado estatus; 0 era el estatus diferente el que le permitía el acceso a los alucinógenos.

En Solcor 3 se observan dos fases bien nítidas: una, anterior a las influencias tiwanakotas, y otra, coincidente con el auge de dichas influencias. Esto nos da la extraordinaria posibilidad de tratar el problema también con una perspectiva diacrónica, tanto en el sentido de detectar los cambios en la semiótica de las tabletas, como en relación a los cambios socioculturales que pudieron afectar a sus portadores, como consecuencia de los cambios ideológicos, o a la inversa. Por último, todo este desarrollo nos llevará a reunir antecedentes para inferir el rol sociopolítico inherente a los miembros de la esfera chamánica.

\section{Metodología}

El primer desafío metodológico que hemos debido afrontar ha sido la elaboración del patrón antropofísico y contextual de los portadores de tabletas. Para esto hemos tenido, por un lado, que ocuparnos de diagnosticar el sexo, la edad, la deformación craneana y los rasgos de variación discontinua de los individuos asociados con objetos psicotrópicos; y por otro, analizar la composición etaria y sexual de las tumbas de esos individuos (en el caso de las que tienen más de un cuerpo). Además, analizar los ajuares funerarios, para tratar de detectar constantes factuales comunes a este grupo.

Para la determinación sexual de los adultos se consideró, en primer lugar, la morfología de la pelvis, por ser la que da mayor margen de seguridad, secundada por la cráneo-facial. En el análisis pélvico se usaron los siguientes rasgos: abertura de la escotadura ciática mayor, surcos preauriculares, cavidades dorsosinfisiales, ángulo subpúbico, forma de la sínfisis púbica y tamaño de la cavidad pélvica. En la morfología craneana se consideró: el desarrollo de las apófisis mastoideas, desarrollo del torus supraorbitario, desarrollo del torus occipital, borde orbitario superior, desarrollo del hueso malar, y desarrollo de la rama ascendente de la mandíbula.

Para la determinación de la edad, en los individuos subadultos, se empleó el método de Ubelaker (1978) que considera la calcificación y la erupción dentaria. Cuando no estaban presentes los dientes, pero sí los huesos largos, se calculó la edad a base del largo de los mismos, por la tabla de Johnson (en Bass 1971) y, principalmente, por comparación de medidas de los huesos largos de individuos cuyas edades habían sido determinadas más seguramente por el desarrollo dental. En individuos entre los 10 y los 20 años se usó el criterio de la unión de las epífisis de los diferentes huesos del esqueleto; en estas edades el desarrollo dental y el largo de los huesos ya no son especialmente concluyentes.

Los métodos empleados en los adultos fueron aquellos relacionados con los cambios ocurridos en la superficie de la sínfisis pubiana (Todd 1920; Brooks 1955; McKern y Stewart 1957; Gilbert y McKern 1973; Meindl et al. 1985); se usó, además, el método para evaluar el proceso de sinostosis de las suturas craneanas (Meindl y Lovejoy 1985) y el que estudia las modificaciones ocurridas en la superficie auricular del ílium (Lovejoy et al. 1985). Las edades determinadas por cada uno de los métodos fueron promediadas, para obtener la edad biológica estimada del individuo. De acuerdo a los criterios empleados, establecimos fajas etarias en rangos de cinco años cada una desde 0 hasta 60 años. Encontramos también algunos individuos en edades in útero (fetos).

Para el análisis de la deformación craneana nos basamos en el trabajo de Droessler (1981), clasificando las alteraciones morfológicas del cráneo de acuerdo a los huesos afectados y al grado de aplanamiento, en lugar de encuadrarlas en las tipologías de deformación tradicionales. De esta forma, encontramos dos tipos de deformaciones simples: frontal y lambdoidal, y dos compuestas: fronto-occipital (equivalente a la tabular oblicua), y fronto lambdoidal (equivalente a la tabular erecta). Se consideró como cráneos no deformados, aquellos que presentaron cero grado de deformación en todos los huesos.

El sexo y la edad aportaron tanto al patrón biológico como al cultural. Estos rasgos, considerados a 
nivel general del grupo de portadores, mostraron el comportamiento demográfico del grupo dentro de la población como estamento etario, y la proporción de hombres, mujeres y niños. En cambio, los mismos elementos analizados desde el punto de vista de su composición en las tumbas entregaron datos netamente culturales, reflejos de la organización social y familiar del grupo en cuestión y del tratamiento que la sociedad dio a los chamanes.

Dentro de la posibilidad alternativa de que los portadores de tabletas (o sus asociados) fueran foráneos o locales, hemos optado por conceder mayor importancia al estudio de los rasgos no-métricos que a los rasgos métricos, porque la heredabilidad de los primeros es mayor, y están menos afectados por las condiciones ambientales; en consecuencia, permiten detectar un mayor grado de afinidad o de distancia genética entre grupos humanos. Por otro lado, las observaciones métricas se ven seriamente comprometidas en las poblaciones en las que las deformaciones craneanas fueron muy frecuentes, como en nuestro caso.

Para el examen de las variables no-métricas o de variación discontinua hemos comenzado por considerar los 35 rasgos descritos por Castro y Quevedo (1984), pero, posteriormente, eliminamos 14 de ellos por su baja representatividad. Los 21 rasgos finalmente considerados fueron analizados estadísticamente, usando dos métodos de distancia biológica: 1) Promedio de Medidas de Divergencia (PMD) (Mean Measure of Divergence), aplicándose las modificaciones señaladas por Anscombe (1948) y; 2) $X^{2}$ de Sanghvi (Sanghvi 1953). ${ }^{3}$

Previamente, y a objeto de tener un mayor control estadístico, se experimentó con 15 rasgos que parecían separar mejor los grupos de análisis de acuerdo a la problemática tratada, encontrándose que los resultados son básicamente los mismos que cuando se trabaja con el grupo total de los 21 rasgos. También, antes de proceder al análisis de distancia biológica, fue aplicado el método de $\mathrm{X}^{2}$ para determinar si las frecuencias de los rasgos diferían significativamente entre los sexos. Hechos los cálculos correspondientes se encontró que no había diferencia significativa (nivel .05), por lo que los grupos sexuales pudieron ser tratados en forma combinada para la determinación de la distancia biológica.

3 Los análisis estadísticos fueron realizados por el Dr. Jeffrey Shipman del Central Arizona College.
En la aplicación de ambos métodos estadísticos se han advertido algunas pequeñas discrepancias entre los resultados aportados por el $\mathrm{X}^{2}$ de Sanghvi y el PDM. Estas discrepancias son atribuidas principalmente al reducido tamaño de la muestra, ya que el PDM es sensible a este factor, mientras que el $\mathrm{X}^{2}$ responde más bien a las diferencias en las frecuencias de los rasgos entre las muestras. Sin embargo, debemos acrecentar que las diferencias observadas aparecen en el análisis del grupo total de 21 rasgos, mientras que en relación al grupo de 15 rasgos, los resultados de ambos métodos son muy similares y concordantes.

Todos los análisis detallados anteriormente se llevaron a efecto también con el resto de la población que carecía de objetos relacionados con alucinógenos, a fin de compararlos con el patrón inferido para los portadores de tabletas. En este nivel de análisis comparativo se incorporó también la presencia de alfarería foránea, como una manera de visualizar la posible vinculación de los chamanes con las redes de tráfico, y la cantidad de tiestos cerámicos en los ajuares, como indicador de estatus.

Hemos restringido nuestro trabajo a 63 de las 117 tumbas excavadas en Solcor 3 (54\% del total excavado). Sólo hemos tomado en consideración las tumbas que, por sus contextos, han sido factibles de ser asignadas fehacientemente a una de las dos fases discriminadas, es decir, una fase pretiwanaku que llamaremos Fase A y, otra donde las influencias Tiwanaku son persistentes y que llamaremos Fase B. ${ }^{4}$ Dado el ámbito del problema que nos interesa, no sólo hemos dejado fuera las tumbas con contextos confusos, sino también un grupo de tumbas de una fase o subfase anterior a la pretiwanaku. ${ }^{5}$

La Fase A tiene por contexto ceramológico la alfarería que ha sido definida por Tarragó, como San Pedro de Atacama Negro Pulido, predominantemente en las formas VII, IX y X; esta última, con su decoración tipo B (Tarragó 1976). En un trabajo anterior sobre Solcor 3 (Bravo y Llagostera 1986) designamos este conjunto de formas como "Patrón A" y lo identificamos con la asociación 6 de Tarragó

4 Dado que recién estamos estructurando una periodificación para San Pedro de Atacama, no queremos todavía aplicar términos definitivos para las fases y subfases, hasta tener claro el panorama general.

5 Nos referimos a las tumbas asociadas con los patrones C y D expuestos en otra publicación (Bravo y Llagostera 1986). 
(1968); reconsideraciones posteriores nos obligan a segregarlo como una asociación específica, y como la última correspondiente a la clásica alfarería negra pulida. Los demás contextos asociados a esta fase han sido dados a conocer en la mencionada publicación de Solcor 3.

Para cronología de la Fase A disponemos de una fecha radiocarbónica de 480 \pm 60 DC (Beta-27572) (tumba 23 de Solcor 3 ) y por similitud de los componentes alfareros, podríamos adoptar también el fechado de la tumba 2532 de Quitor 6 para la que Le Paige (1963) publica una fecha de $250 \pm 150$ DC. Analizando la situación creemos que esa fecha podría ser aceptada, y en consecuencia sería válido considerarla como fecha temprana de la Fase A. Siendo así, esta fase abarcaría estimativamente desde 250 a 450 DC. ${ }^{6}$ Si bien podría haber duda respecto de la fecha inicial, la fecha de término tiene plena coincidencia, como se verá luego, con la fecha de inicio de la Fase B. En la Fase A quedaron incorporadas 30 tumbas con un total de 70 individuos; de éstas, 12 presentan elementos psicotrópicos involucrando a 40 individuos. Esto quiere decir que en esta fase hay un 57\% de la población que, directa o indirectamente, está comprometida con la esfera psicotrópica.

La alfarería de la Fase B podría asimilarse con la que Tarragó nominó Gris Grueso Pulido. Como ella misma comenta, se observan ciertas semejanzas con formas del Negro Pulido, pero la calidad de la cerámica ha disminuido considerablemente. Sus superficies no poseen ya el color negro intenso ni el aspecto bruñido de aquel tipo, y el espesor de sus paredes aumenta en forma notable (Tarragó 1968). Las formas que predominan en Solcor 3 son: 1) vasijas restringidas, esferoides, ovoides y elipsoides, con labios levemente evertidos, algunas con variantes como un corto cuello o pequeñas asas-apéndices verticales; 2) platos de sección de esfera con profundidades variables; 3 ) vasijas aproximadamente similares a la forma IX de Tarragó (1976), pero mucho menos restringidas; 4) pucos hemiesféricos y, 5) pucos troncocónicos invertidos, algunos con una de las mitades (sección vertical) roja y la otra, negra. Este conjunto ceramológico fue clasificado

\footnotetext{
6 Tenemos una fecha por termoluminiscencia de $720 \pm 120$ DC para la tumba 11 de Solcor 3 (Berenguer et al. 1986). Sin embargo, ante la coherencia observada con las fechas radiocarbónicas, ésta nos parece cuestionable.
}

en el anterior trabajo de Solcor 3, como Patrón B y allí también se describieron los contextos asociados (Bravo y Llagostera 1986).

Para la Fase B tenemos tres dataciones radiocarbónicas: una de 480 \pm 80 DC (Beta-27192), coincidente con la de la tumba 23 de la Fase A; las otras son de $570 \pm 60$ DC (Beta-22461) y, 680 \pm 90 DC (Beta-27191). Además se dispone de una fecha por termoluminiscencia de 510 \pm 150 DC (Berenguer et al. 1986) para una tumba con contexto asignable a la Fase B. Todas estas fechas son coherentes para señalar el comienzo y la progresión cronológica de esta fase; sin embargo, el fin de la misma no es claro, ya que para Solcor 3 tenemos fechas por termoluminiscencia de $850 \pm 110$ DC y $920 \pm 120$ DC (Berenguer et al. 1986) y, por $\mathrm{C}^{14}$, de 910 \pm 50 DC (Beta-27573).

Estas últimas dataciones están asociadas a materiales tiwanakotas, pero sin indicadores ceramológicos que nos permitan encuadrarlos dentro de la Fase $\mathrm{B}$, tal como la hemos definido. Es posible que más adelante se pueda segregar otra fase o subfase para englobar estas influencias tiwanakotas. Lo cierto es que la fecha más tardía que tenemos al momento para un contexto típico de la Fase B es la de $680 \pm 90 \mathrm{DC}$, procedente de la tumba 2 . Un total de 33 tumbas reunieron los requisitos para ser consideradas dentro de la Fase B, incorporando una población de 64 individuos. De estas 33 tumbas, 15 contienen tabletas y/o tubos en sus ajuares funerarios comprometiendo a 30 personas. Según esto, para la Fase B de Solcor 3 se daría un $46 \%$ de la población involucrada con objetos de la psicotropía.

Nueve, del total de las 38 tumbas con objetos para alucinógenos, han presentado dificultades para asignarlas a alguna de las dos fases, por ausencia de alfarería o por la no clara definición del contexto cerámico (ver Anexo). Sin embargo, si bien es cierto que no ha sido posible considerarlas en la información cronologizada, las hemos utilizado para incrementar, a nivel general, los datos personales de los portadores de tabletas. Otra situación que hemos tenido que afrontar en cuanto a información restringida han sido los casos de tumbas múltiples, donde no es seguro a cuál de los individuos están asociados los objetos en cuestión. En la Fase A, de cinco tumbas múltiples, hay tres en las que no es posible determinar cuál de todos los individuos es el portador; en la Fase B, de siete, tres están en la misma situación. 
Del total de tumbas con objetos para inhalar alucinógenos, 23 tienen tabletas y tubos, siete sólo tabletas y seis sólo tubos. Frente a esto, naturalmente surgió la pregunta, sobre si este hecho obedece a alguna disposición intencional relacionada con sexo, edad, número de individuos en las tumbas, estatus o cronología. Efectuados los correspondientes cálculos estadísticos observamos que esta situación no está sujeta a ninguna de las variables planteadas. Por esta razón, hemos optado por considerar por igual la presencia de uno o de los dos objetos.

\section{Equipo psicotrópico}

El equipo inhalatorio típico de Solcor 3 consiste en una bolsa textil que contiene una tableta, un tubo, una cucharilla, y una o dos bolsas de cuero con los polvos alucinógenos. En varios casos (p.e., tumbas 10 y 112) el ajuar psicotrópico incluye una bolsa de cuero adicional con una pequeña cantidad de piedra de oxidado de cobre triturada (Figuras 1 y 2). Sin embargo, estas bolsas también están presentes en tumbas que no poseen implementos del complejo alucinógeno, por lo cual pensamos que no son parte de dicho complejo, sino más bien, amuletos.

Los equipos pertenecientes a las tumbas 106, $107 \mathrm{y}$ 112 deben ser descritos en detalle debido a que sus componentes son representativos del sitio e ilustran claramente los diversos tipos de ajuares inhalatorios. ${ }^{7}$ El ajuar de la tumba 106 estaba dentro de una bolsa textil policroma, cerrada con una atadura de cuerda trenzada bícroma (blanco y negro). Contenía un tubo de madera con boquilla hechos en una sola pieza, una bolsita de cuero bastante deteriorada, dos cucharillas de madera, una espátula de hueso, y un recipiente hecho de hueso de camélido. Este conjunto no incluye tableta y no posee decoración en sus componentes, a excepción de la bolsa textil.

El equipo de la tumba 107 es de los más complejos encontrados en San Pedro de Atacama (Figuras 3 y 4). Una banda policroma en urdiembre transpuesta, de aproximadamente $6 \mathrm{~cm}$ de ancho, rodea en unas cuatro vueltas y media una bolsa gruesa de malla aterciopelada roja. Dentro de esta bolsa se halló una tableta con iconografía tiwanakota. Detrás de la tableta había dos bolsitas de cuero cerradas con un

7 Para la descripción de la parafernalia inhalatoria tumba por tumba, y de los contextos funerarios de dichas tumbas, ver Anexo al final de este artículo. cordel bícromo (amarillo y verde). Junto a las dos bolsitas se encontró un tubo de madera envuelto con una lámina de oro y con los dos extremos enchapados en el mismo material. El ajuar también incluye una cucharilla de madera sin decoración.

El individuo sepultado en la tumba 112 lleva dos bolsas con ajuar inhalatorio (Figuras 5, 6, 7 y 8). Las dos bolsas son muy similares, en estructura y en decoración. Las dos son policromas, en urdiembre transpuesta en su parte superior, y faz de urdiembre llana en la parte inferior. Para nuestros propósitos ilustrativos se describirá solamente el contenido de una de éstas ( $n^{\circ} 3902$ ). Esta bolsa contiene otra en su interior, gruesa, aterciopelada, en color rojo, como la que se describió antes para la tumba 107. Dentro de ella se ubicó una tableta con extensión planiforme sin decoración, dos bolsas de cuero con atadura bícroma (amarillo y verde), una bolsa de cuero pequeña con gravilla de oxidado de cobre y una cucharilla de madera con bifurcación en su extremo superior. Además de esta bolsa roja y su contenido, la bolsa policroma contenía un tubito fino de caña con embarrilado en un extremo, un recipiente de caña, y una pequeña madeja de hilo color café.

En resumen, los elementos utilizados en la inhalación de polvos alucinógenos en Solcor 3 se limitan a tabletas, tubos, cucharillas y bolsas para el polvo psicoactivo. Ninguno de los 38 equipos inhalatorios de este sitio incluye morteros y/o pilones. Estos objetos, que probablemente fueron empleados en la preparación de los finos polvos, se han encontrado en algunas tumbas, pero no en relación directa con el paquete inhalatorio.

Las tabletas de Solcor 3 muestran una limitada variedad morfológica. Doce de ellas exhiben un panel sin decoración; éstas varían ligeramente, algunas con lados rectos (rectangulares), otras con lados convexos o abanicados (trapezoidales), y tres con lados cóncavos. ${ }^{8}$ La conjunción entre el panel y la cavidad es, en su mayoría, continua, sin marco o delimitación notoria en el área del recipiente al confluir con el panel. En un solo caso (n $\left.{ }^{\circ} 1909\right)$ el panel está deslindado de la cavidad por un borde en relieve. Este tipo de tabletas con paneles planos y sin decoración es el grupo de mayor representación en el Museo de San Pedro de Atacama. De las 477

8 Las ilustraciones de todas las tabletas de Solcor 3 se encuentran en las Figuras 5 a 8, ordenadas por su número de registro. 


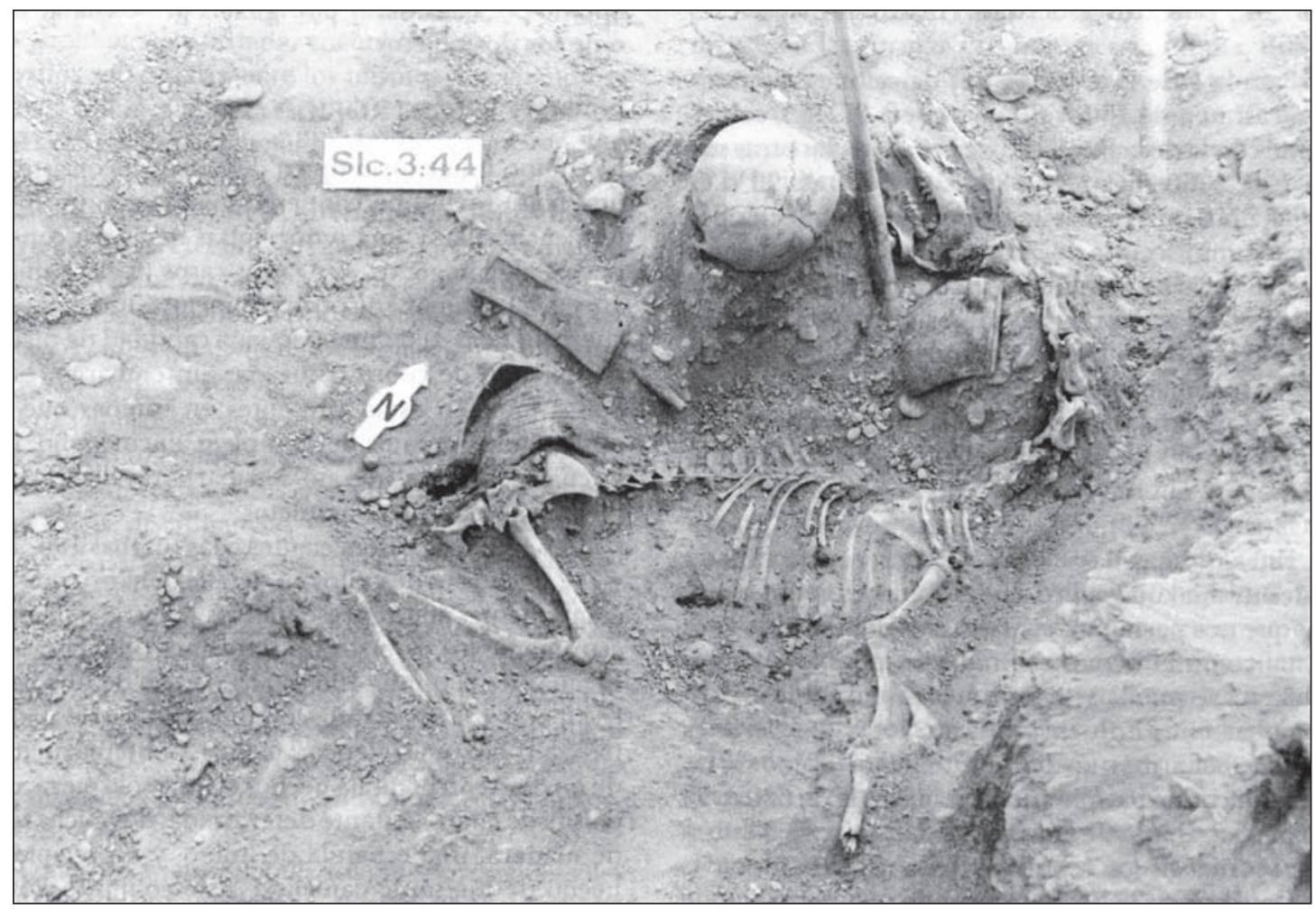

Figura 1. Tumba 44 de Solcor 3: Se observa la posición del complejo alucinógeno in situ, junto con la ofrenda de un camélido.

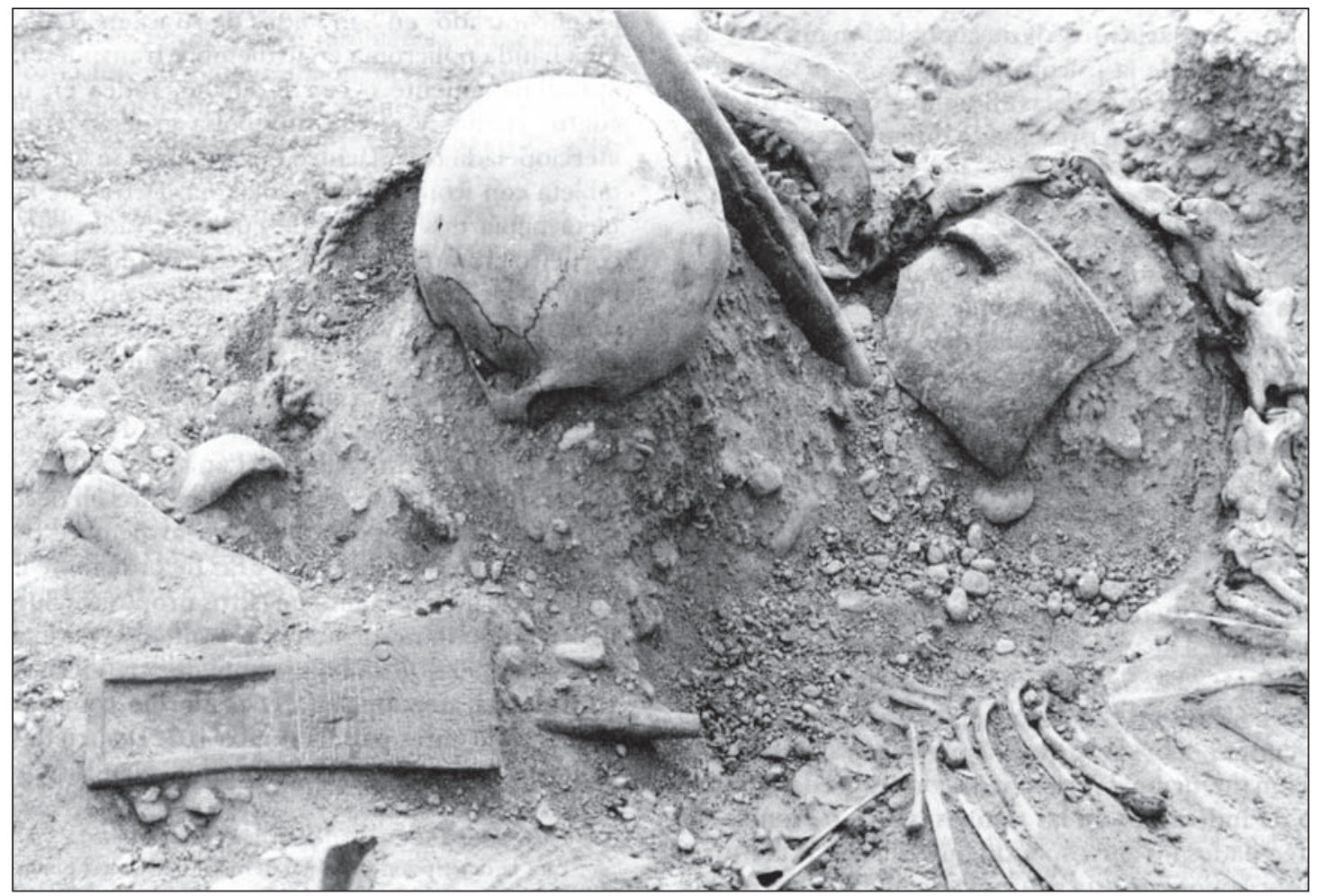

Figura 2. Detalle de la fotografía anterior, mostrando la tableta ${ }^{\circ} 1874$ y el tubo $\mathrm{n}^{\circ} 1873$. 


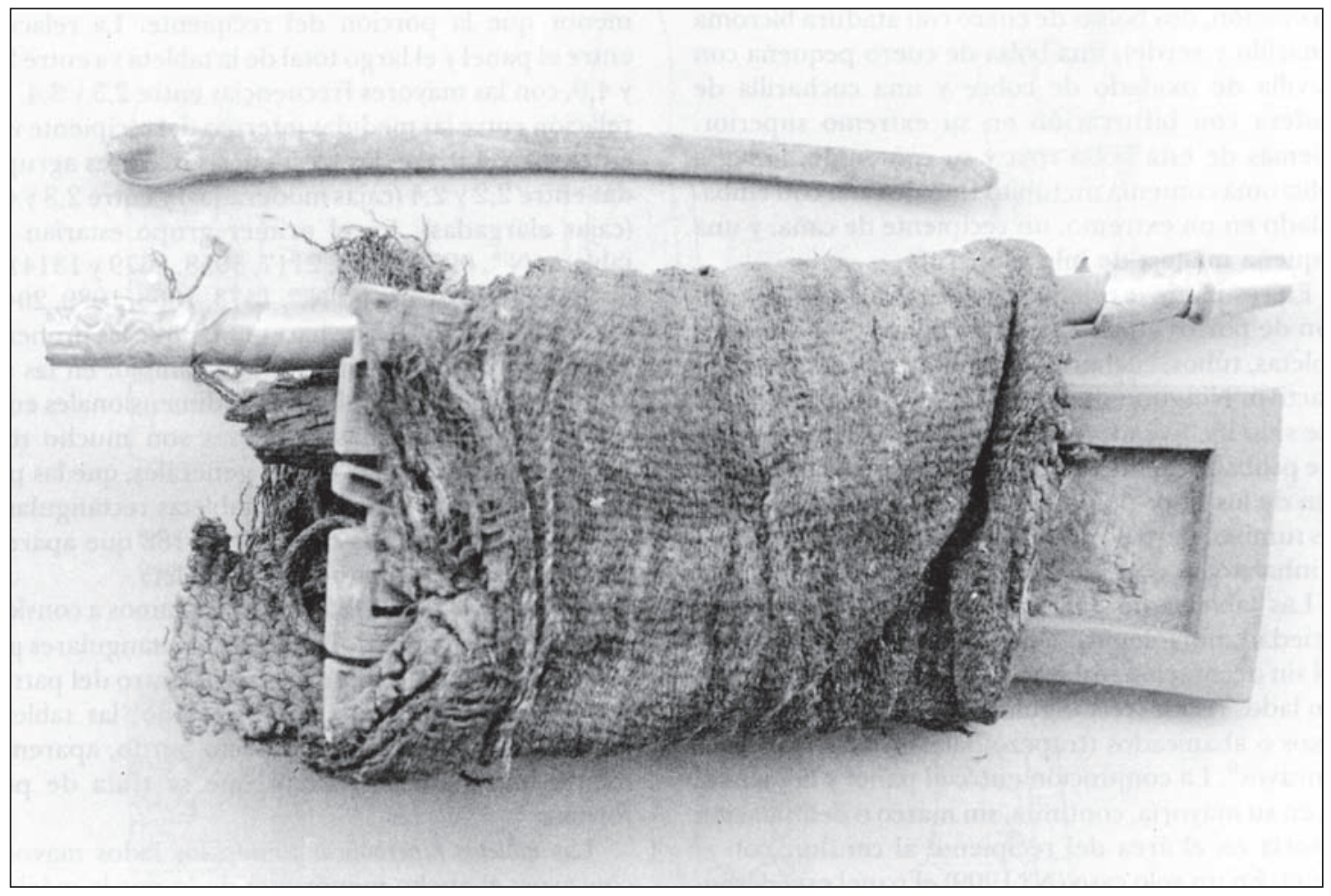

Figura 3. Tumba 107 de Solcor 3: Paquete inhalatorio.

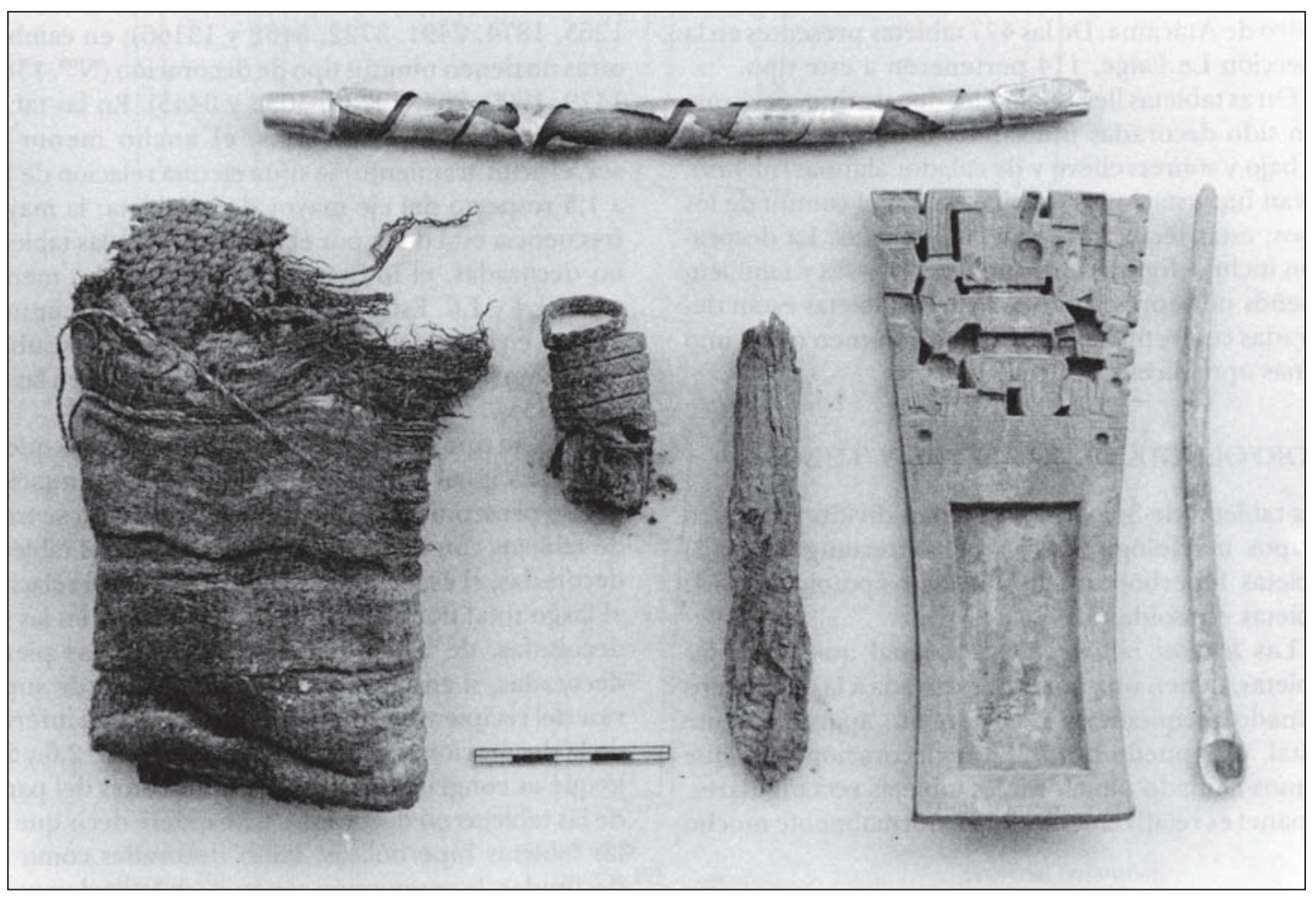

Figura 4. Elementos del paquete inhalatorio de la tumba 107: Faja envolvente, dos bolsitas de cuero, tableta, cucharilla y tubo recubierto con lámina de oro. 


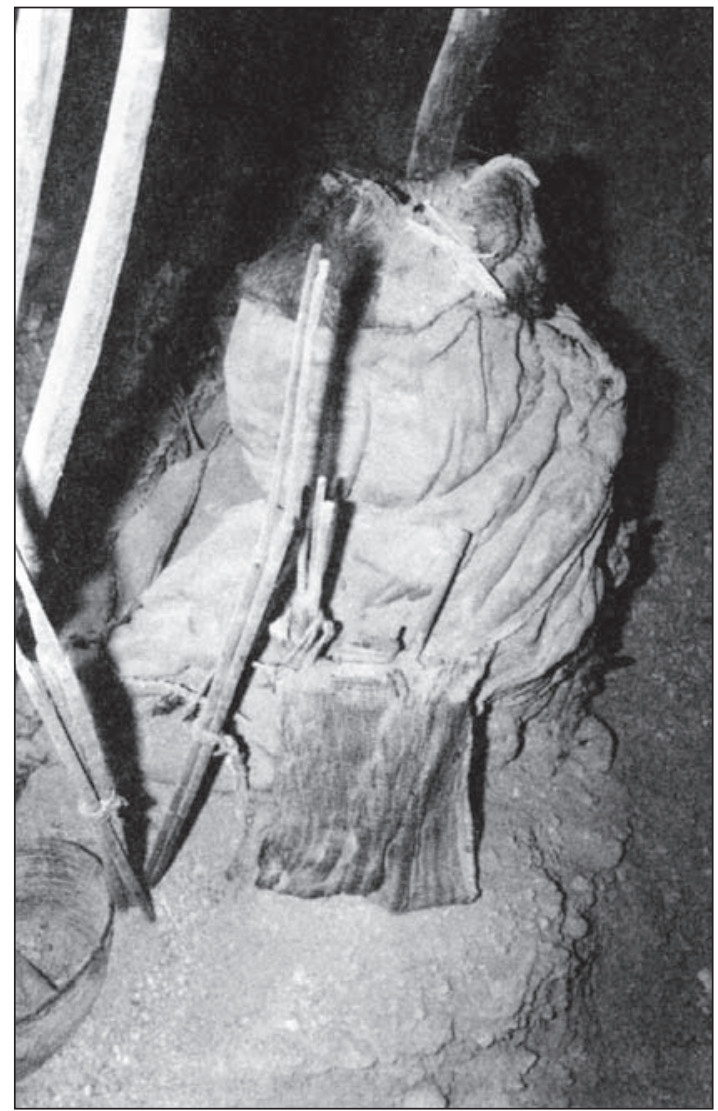

Figura 5. Tumba 112 de Solcor 3: Cuerpo con dos bolsas que contienen objetos para inhalar alucinógenos.

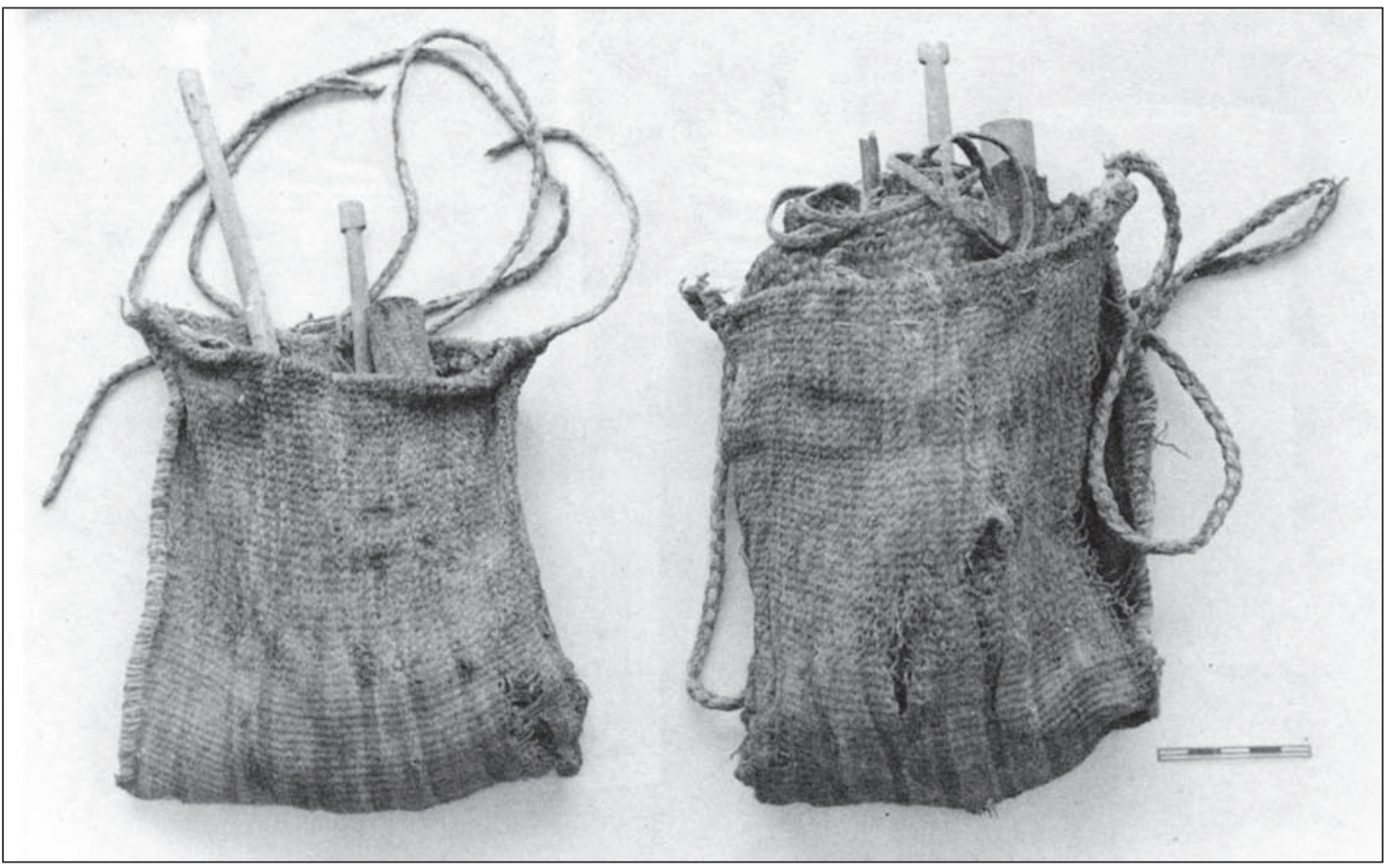

Figura 6. Bolsas no $3901 \mathrm{y} \mathrm{n}^{\circ} 3902$ de la tumba 112 de Solcor 3. 


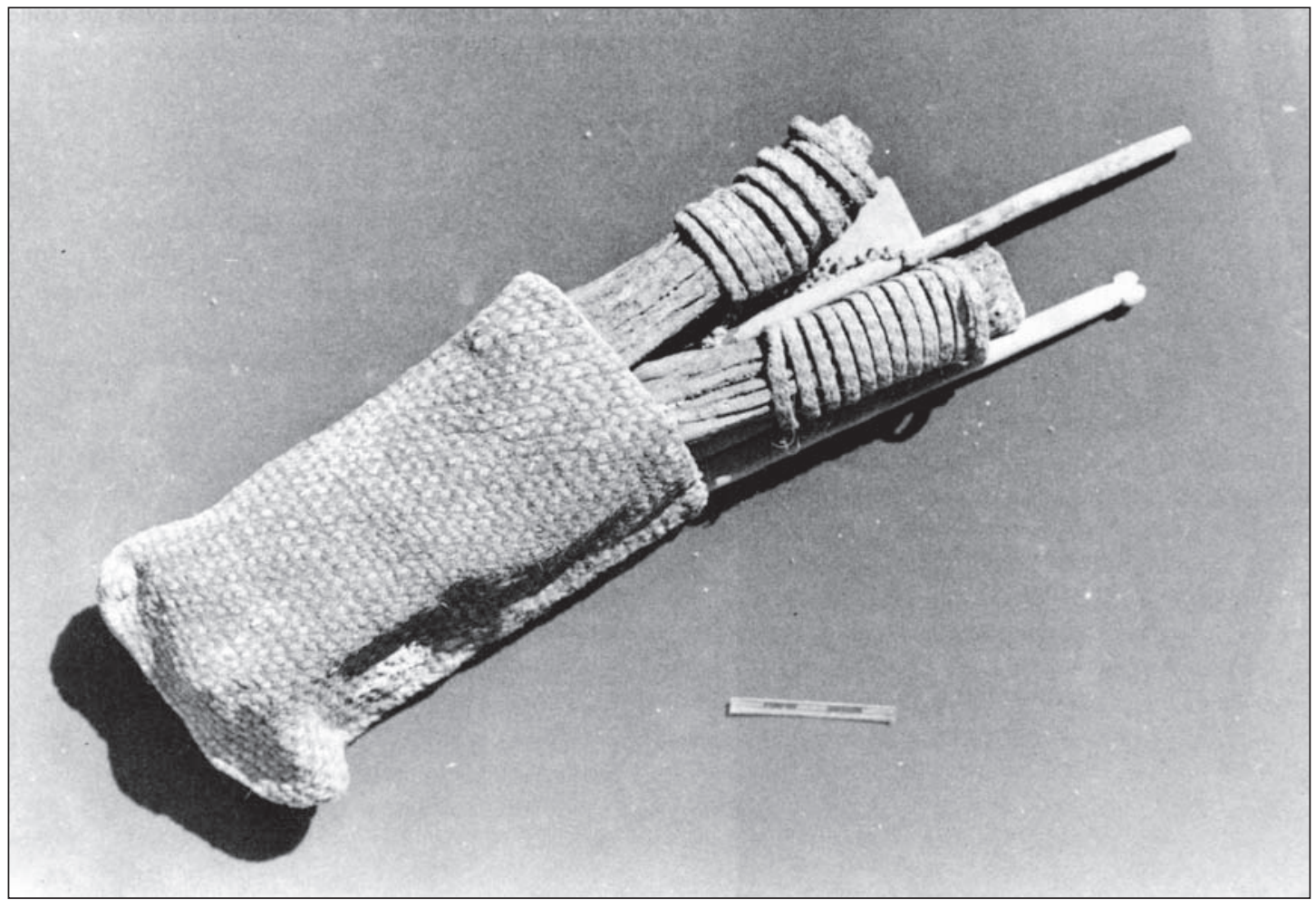

Figura 7. Bolsa n ${ }^{\circ} 8443$ que se encontraba dentro de la bolsa n 3902 , en la tumba 112 de Solcor 3.

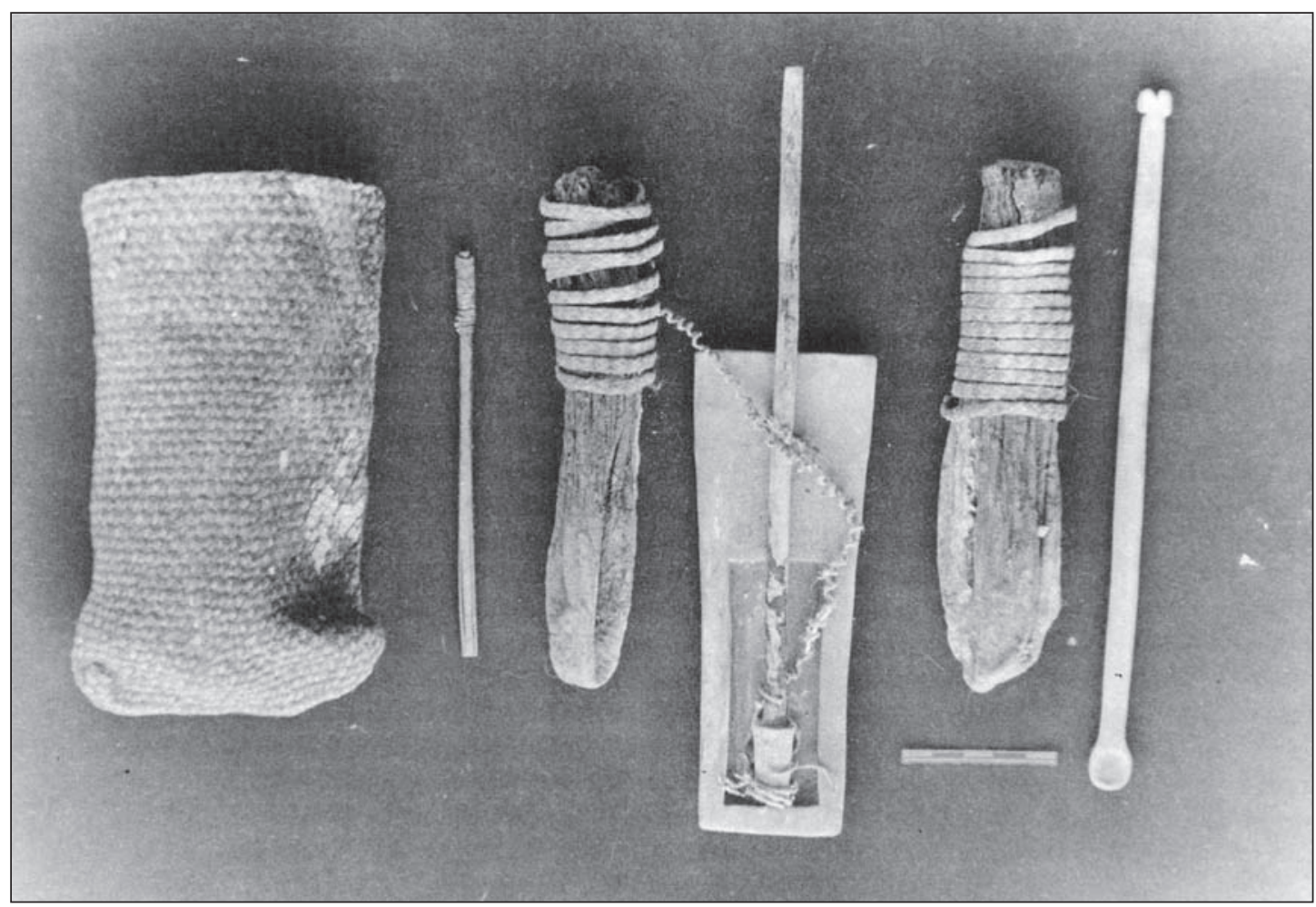

Figura 8. Elementos del complejo alucinógeno contenidos en la bolsa n ${ }^{\circ} 8443$ : Tubito embarrilado, dos bolsitas de cuero, tableta y tubo, y cucharilla. 
tabletas presentes en la colección Le Paige 114 pertenecen a este tipo.

Otras tabletas llevan paneles de este tipo, pero que han sido decoradas utilizando técnicas de grabado, de bajo y sobrerrelieve y de calado; algunas, incluso, llevan incrustaciones de piedras; en el común de los casos, estas técnicas se dan combinadas. La decoración incluye figuras antropo o zoomorfas y también, diseños no representativos. Varias tabletas están decoradas con representaciones en volumen o con uno o más apéndices.

\section{Morfología de tabletas y tubos}

Las tabletas de Solcor 3 se pueden dividir en cuatro grupos morfológicos: 1) tabletas rectangulares, 2) tabletas hiperbólicas, 3) tabletas trapezoidales y 4) tabletas elipsoidales (Figuras 9, 10 y 11).

Las tabletas rectangulares, al igual que todas las tabletas, tienen una porción excavada a la que hemos llamado recipiente, y una porción, aparentemente distal, que puede o no llevar decoración, a la que hemos llamado panel. En las tabletas rectangulares, el panel es relativamente corto, normalmente mucho menor que la porción del recipiente. La relación entre el panel y el largo total de la tableta va entre $2.0 \mathrm{y}$ 4.0, con las mayores frecuencias entre 2.3 y 3.4 . La relación entre las medidas internas del recipiente van entre 2.2 y 4.0 , con las frecuencias mayores agrupadas entre 2.2 y 2.4 (cajas moderadas) y entre 2.8 y 4.0 (cajas alargadas). En el primer grupo estarían las tabletas $\mathrm{n}^{\text {os }} 0958,1188,2117,3058,3679$ y 13141 , $\mathrm{y}$ en el segundo grupo las $\mathrm{n}^{\text {os }} 1573,1668,1989$, 2046, 2207, 2381 y 2764. Cabe hacer notar que las primeras presentan un panel tableado, en cambio, en las segundas se han tallado figuras tridimensionales en el panel. Por último, las segundas son mucho más oblongas en sus proporciones generales, que las primeras. La cara inferior de las tabletas rectangulares es recta, excepto en la tableta $\mathrm{n}^{\circ} 1188$ que aparece convexa, por la curvatura de la tableta.

Las tabletas $n^{\text {os }} 1425$ y 8438 las vamos a considerar como variedades de las tabletas rectangulares por tener los lados mayores convexos, dentro del patrón general de rectángulo. Por otro lado, las tabletas $\mathrm{n}^{\text {os }} 3058$ y 3679 , por su aspecto burdo, aparentemente inacabadas, creemos que se trata de preformas.

Las tabletas hiperbólicas tienen los lados mayores cóncavos; el ancho menor está dado por la máxima inflexión de los lados y se ubica normalmente en la mitad inferior del objeto. Algunas de estas tabletas presentan el panel decorado $\left(\mathrm{n}^{\mathrm{os}} 1045,1075\right.$, $1112,1265,1874,2491,3722,8432$ y 13166); en cambio, otras no tienen ningún tipo de decoración (n ${ }^{\text {os }} 1387,1479,1909,2648,2725,3038$ y 8445$)$. En las tabletas hiperbólicas decoradas, el ancho menor (o sea, el acinturamiento) se sitúa en una relación de 1.2 a 1.5 respecto del eje mayor de la tableta; la mayor frecuencia está dada por el índice 1.3. En las tabletas no decoradas, el índice nos ubica el ancho menor entre 1.4 y 1,6. Estos datos muestan que el acinturamiento en las tabletas hiperbólicas decoradas se ubica más abajo (más cerca del borde inferior) que en las no decoradas.

En este tipo de tabletas hay una tendencia a que el panel sea igual o mayor que el recipiente, situación que se presenta mayormente definida según se trate de tabletas con decoración o sin ella. En las tabletas decoradas, el espacio que ocupa el panel, en relación al largo total de la pieza, va de 1.8 a 2.1, y en las no decoradas, de 2.1 a 2.4. En el caso de las piezas decoradas, si en lugar de considerar el borde superior del recipiente tomamos la línea grabada inferior de la decoración, nos da una relación entre 2.0 y 2.4 lo que es congruente con las proporciones del panel de las tabletas no decoradas. Esto quiere decir que en las tabletas hiperbólicas, tanto decoradas como no decoradas, la proporción canónica del panel se mantiene constante en relación al tamaño de la tableta. Para resolver el problema de proporciones en las decoradas, sus artífices han restringido el recipiente. Bajo este análisis, la tableta $\mathrm{n}^{\circ} 2725$ que aparece como excepción dentro de las no decoradas (índice 1.8) resultaría ser una preforma que estaba destinada a ser decorada; asimismo, la tableta ${ }^{\circ} 1909$ (índice 4.3) podría interpretarse como una pieza a la cual se le quebró el panel y se arregló recortándolo; sin embargo, la proporción del recipiente no corrobora este supuesto; sólo queda pensar que se trata de una tableta atípica a los cánones anteriores.

Prácticamente en todas las tabletas hiperbólicas, la cara inferior es inflexionada (convexa) en el eje longitudinal, lo que se aprecia claramente al observarlas de perfil. Hace excepción a esta regla la tableta $\mathrm{n}^{\circ} 1909$ que tiene una cara inferior plana y levemente cóncava en sentido transversal. Otro patrón constante de las tabletas hiperbólicas es un menor espesor del borde distal, para ir engrosando hacia la porción del recipiente. En algunos casos, ese mayor grosor del perfil del recipiente se mantiene 


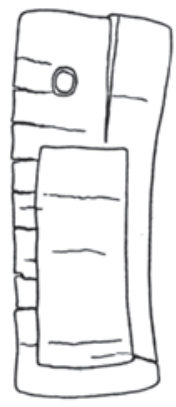

$N^{\circ} 958$

(tumba 1)

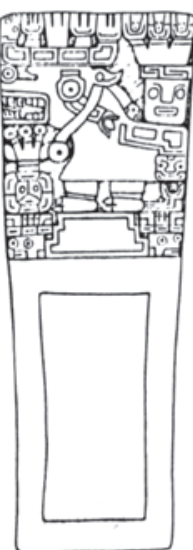

$\mathrm{N}^{\circ} 1075$

(tumba 5)

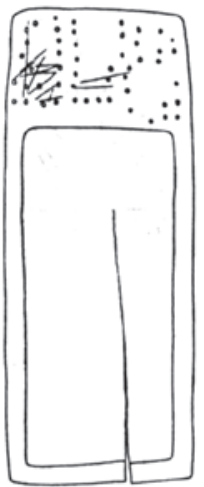

$\mathrm{N}^{\circ} 1188$

(tumba 10)

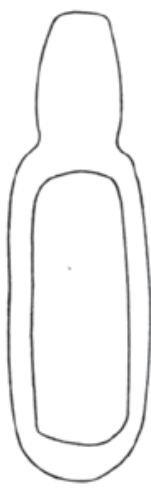

$N^{\circ} 1023$

(tumba 3)

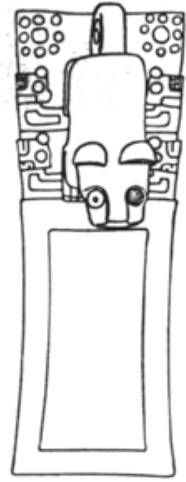

$\mathrm{N}^{\circ} 1112$

(tumba 6)

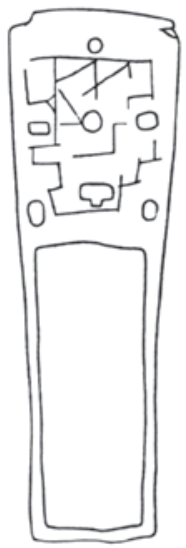

$\mathrm{N}^{\circ} 1265$

(tumba 12)

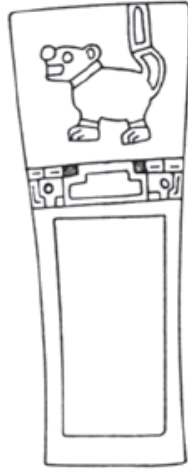

$N^{\circ} 1045$

(tumba 4)
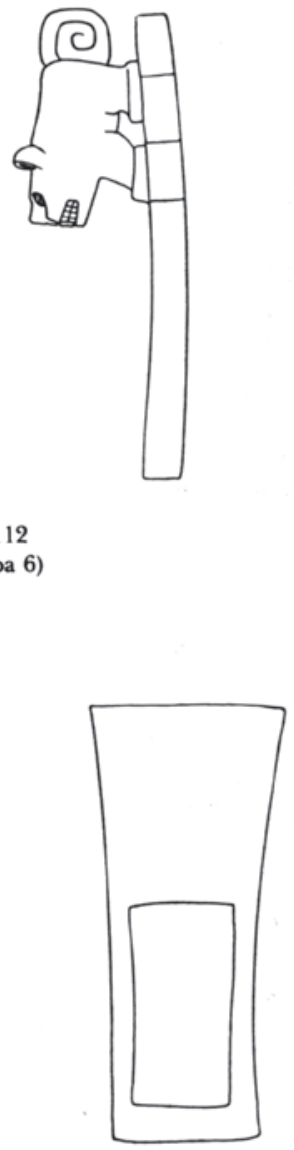

$\mathbf{N}^{\circ} 1387$

(material removido)

Figura 9. Tabletas de Solcor 3. 


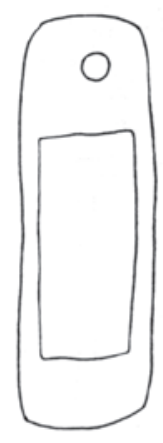

$\mathrm{N}^{\circ} 1425$

(tumba 16)

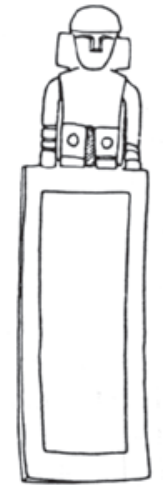

$\mathrm{N}^{\circ} 1688$

(tumba 29)

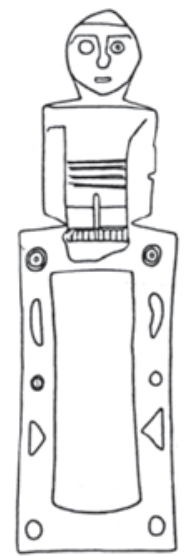

No 1989

(tumba 50)

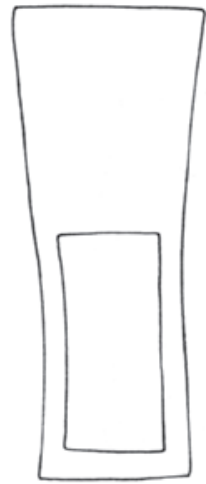

$\mathrm{N}^{\circ} 1479$

(tumba 20)

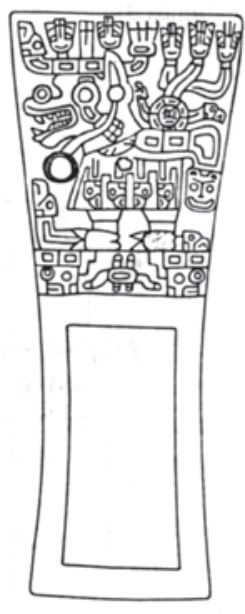

$\mathrm{N}^{\circ} 1874$

(tumba 44)

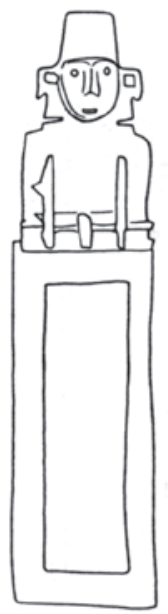

N ${ }^{\circ} 2046$

(tumba 52)

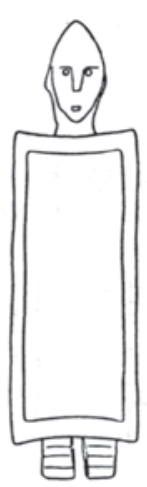

$\mathrm{N}^{\circ} 1573$

(tumba 24)

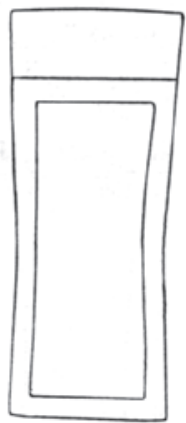

$\mathrm{N}^{\circ} 1909$

(tumba 47)

Figura 10. Tabletas de Solcor 3. 


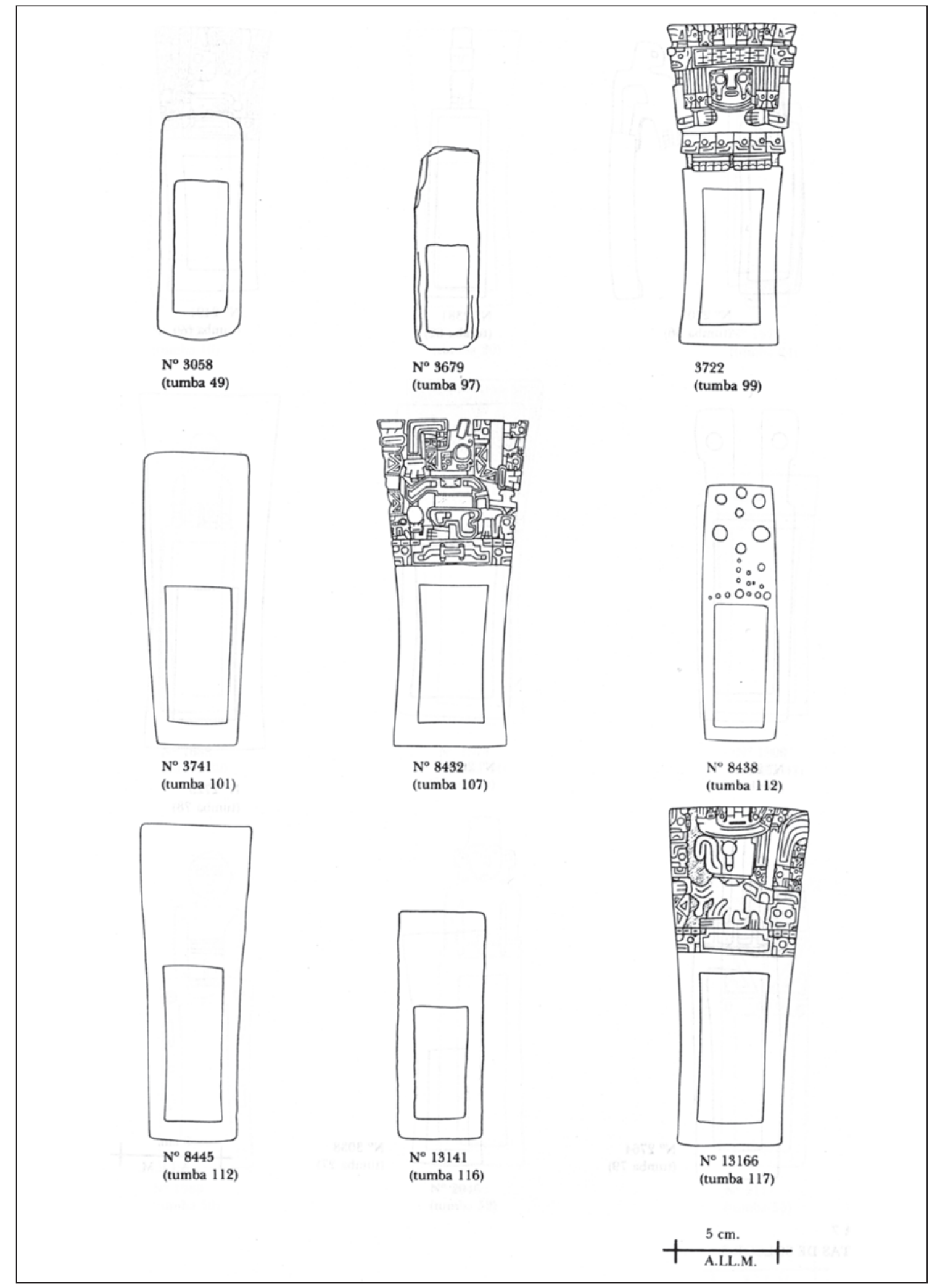

Figura 11. Tabletas de Solcor 3. 
constante hasta el borde inferior o proximal; en otros casos vuelve a disminuir hacia este último borde, aumentando la inflexión de la cara inferior de la tableta.

Sólo dos ejemplares de Solcor 3 podrían ser definidos como tabletas trapezoidales. La tableta $\mathrm{n}^{\circ} 2518$ lleva en lugar del panel dos apéndices que se podrían definir como claviformes tableados, cada uno con una cavidad que seguramente alojó una incrustación. La tableta $\mathrm{n}^{\circ} 3741$ es de panel llano sin decoración; los bordes mayores de esta tableta son levemente convexos.

Por último, hay una tableta $\left(\mathrm{n}^{\circ} 1023\right)$ que se podría clasificar en el grupo de tabletas elipsoidales, por la forma de su recipiente. En el lugar del panel lleva un apéndice troncocónico tableado, de lados mayores convexos.

Los tubos tienen un largo que va de 160 a $240 \mathrm{~mm}$ (hay dos excepciones de mayor longitud), y un diámetro entre 6 y $10 \mathrm{~mm}$. En el extremo proximal llevan una porción más voluminosa, a la que hemos llamado "boquilla" a falta de un término más adecuado, destinada a la aplicación nasal; su forma generalmente es troncocónica simple, aunque hay dos casos en los que aparece como dos troncoconos superpuestos. Esta boquilla puede ser sobrepuesta o tallada en una sola pieza junto con el tubo. El tubo propiamente tal es siempre cilíndrico; en algunos casos es simple, sin ningún adorno y, en otros, puede llevar motivos esculpidos o grabados, generalmente en el extremo terminal y/o en el centro del tubo (Figuras 12 y 13). Hay tres casos (n $\left.{ }^{\text {os }} 1076,2768,3723\right)$ en los que se ha tallado una pequeña argolla en la conjunción de la boquilla con el tubo, posiblemente con el propósito de pasar un cordelillo por el orificio y colgar algo de él o para colgar el objeto mismo.

\section{Iconografía}

La iconografía de las 34 tabletas procedentes de Solcor 3 puede clasificarse en cuatro grupos básicos: 1) 12 tabletas sin decoración alguna, 2) ocho tabletas que portan iconografía tiwanakota, 3) 12 que poseen figuras humanas o de animales talladas en volumen, y 4) dos que llevan diseños no figurativos.

Las 12 tabletas sin decoración aparentemente no llevan información iconográfica; pero es probable que su forma en general, el contorno del panel, más el tipo de conjunción entre el recipiente y el panel hayan tenido connotaciones significativas. Compárense por ejemplo, la tableta $\mathrm{n}^{\circ} 1023$ con la $\mathrm{n}^{\circ} 1909$ y se observarán marcadas diferencias en la forma del recipiente y del panel. Además, la tableta $\mathrm{n}^{\mathrm{o}} 1909$ posee un prominente borde en relieve que separa el recipiente del panel. Estas diferencias pudieran indicar la posibilidad de signos formales, los cuales pasan desapercibidos debido a nuestra insistencia en separar forma y significado. De ser así, estas supuestas características formales pudieran, probablemente, modificar el significado de los temas y motivos en ellas representados.

En Solcor 3, la iconografía tiwanakota está mayormente asociada a la parafernalia inhalatoria. Ocho tabletas y cinco tubos están decorados con temas reconocidos para el Tiwanaku altiplánico. Además de estas tabletas y tubos, los motivos tiwanakotas aparecen sólo en una vasija cerámica, una bolsa policroma, y una manta. Los artefactos tiwanakotas en Solcor 3 no se asocian unos con otros, o sea, son los únicos objetos con este tipo de decoración en sus respectivas tumbas.

Las tabletas $\mathrm{n}^{\text {os }} 2491$ y 8432 (Figura 15) exhiben temas muy similares. En ambas, una figura antropomorfa de perfil genuflexa porta en una mano un hacha y una cabeza, mientras que en la otra lleva un cetro u objeto similar. Las dos figuras giran hacia su derecha y miran hacia arriba, muestran una prominente nariz y un objeto indeterminado emana de sus bocas. Ambas figuras llevan en sus brazos y piernas marcas que parecen ser indicadores de los huesos. A pesar de estas similitudes, existen grandes diferencias en los detalles que las componen y en sus características formales. La tableta $\mathrm{n}^{\circ} 2491$ está tallada en un bajorrelieve plano. La figura genuflexa se encuentra sobre una plataforma escalonada conteniendo un pequeño rectángulo, que es flanqueada por cabezas de pez, motivo típico del estilo tiwanakota (para una discusión de los motivos tiwanakotas en San Pedro de Atacama ver Torres 1987: 90-96). En la tableta n 8432 la figura se yergue sobre una plataforma escalonada, dentro de la cual se encuentra inciso un motivo que es repetido en varias ocasiones en otras tabletas de San Pedro de Atacama (Torres 1987: Lám. 76), y que aparece también en la escultura monumental de Tiwanaku en Bolivia (Posnansky 1945, vol. 1: Fig. 113a). Además, la figura en la tableta $n^{\circ} 8432$ está delineada por la técnica de calado, y no por bajorrelieve como en la n 2491 . 


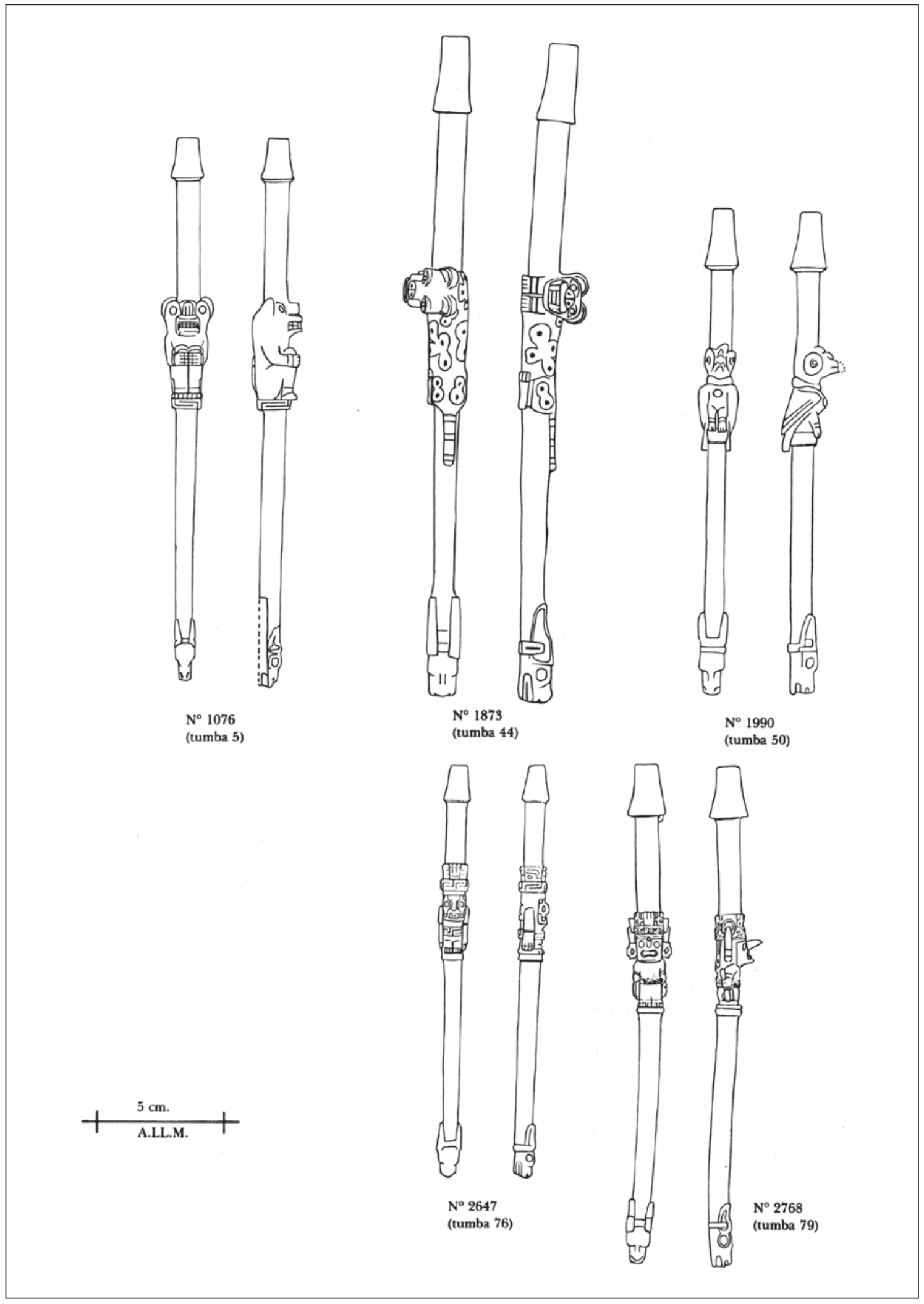

Figura 12. Tubos inhalatorios de Solcor 3. 


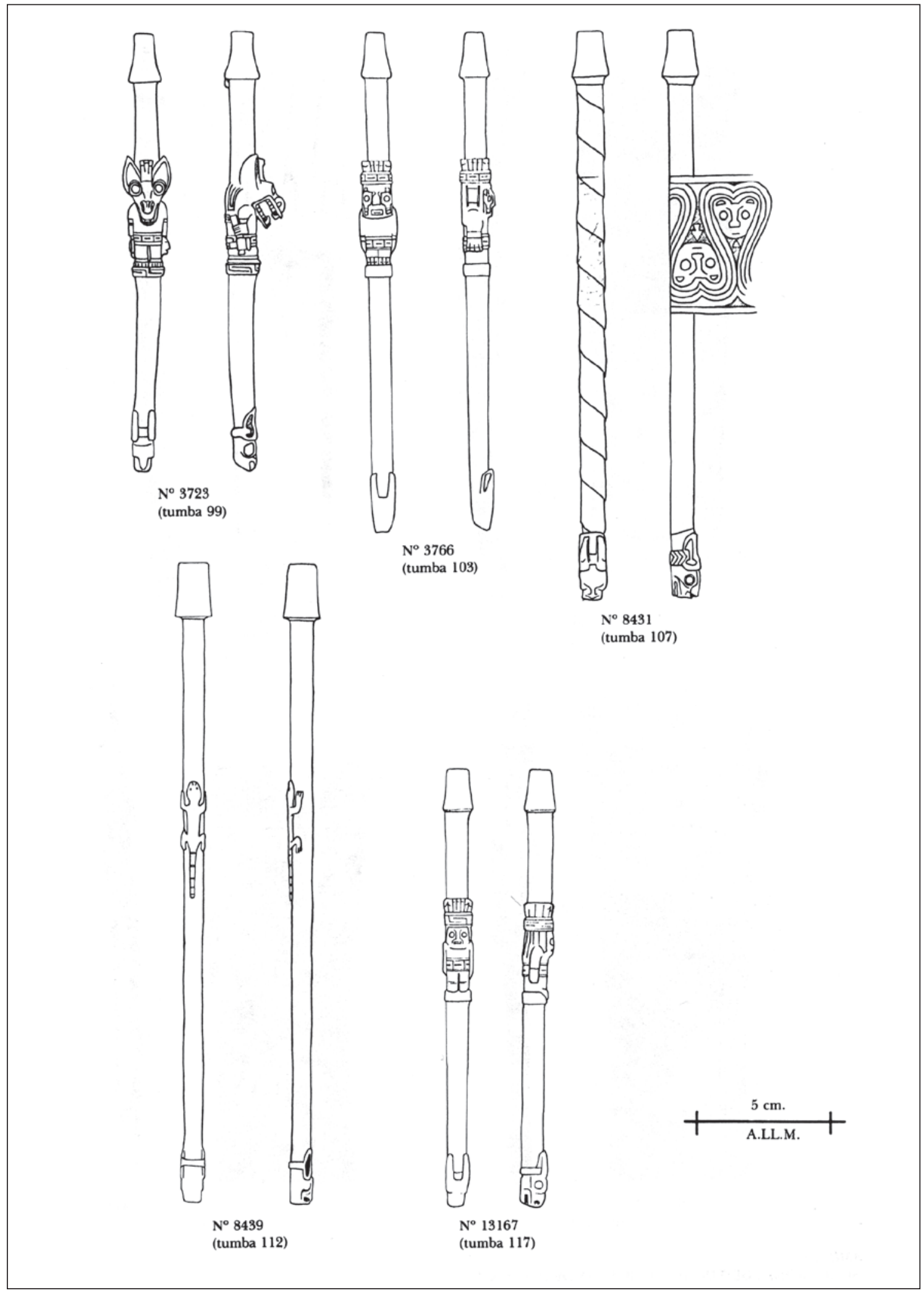

Figura 13. Tubos inhalatorios de Solcor 3. 


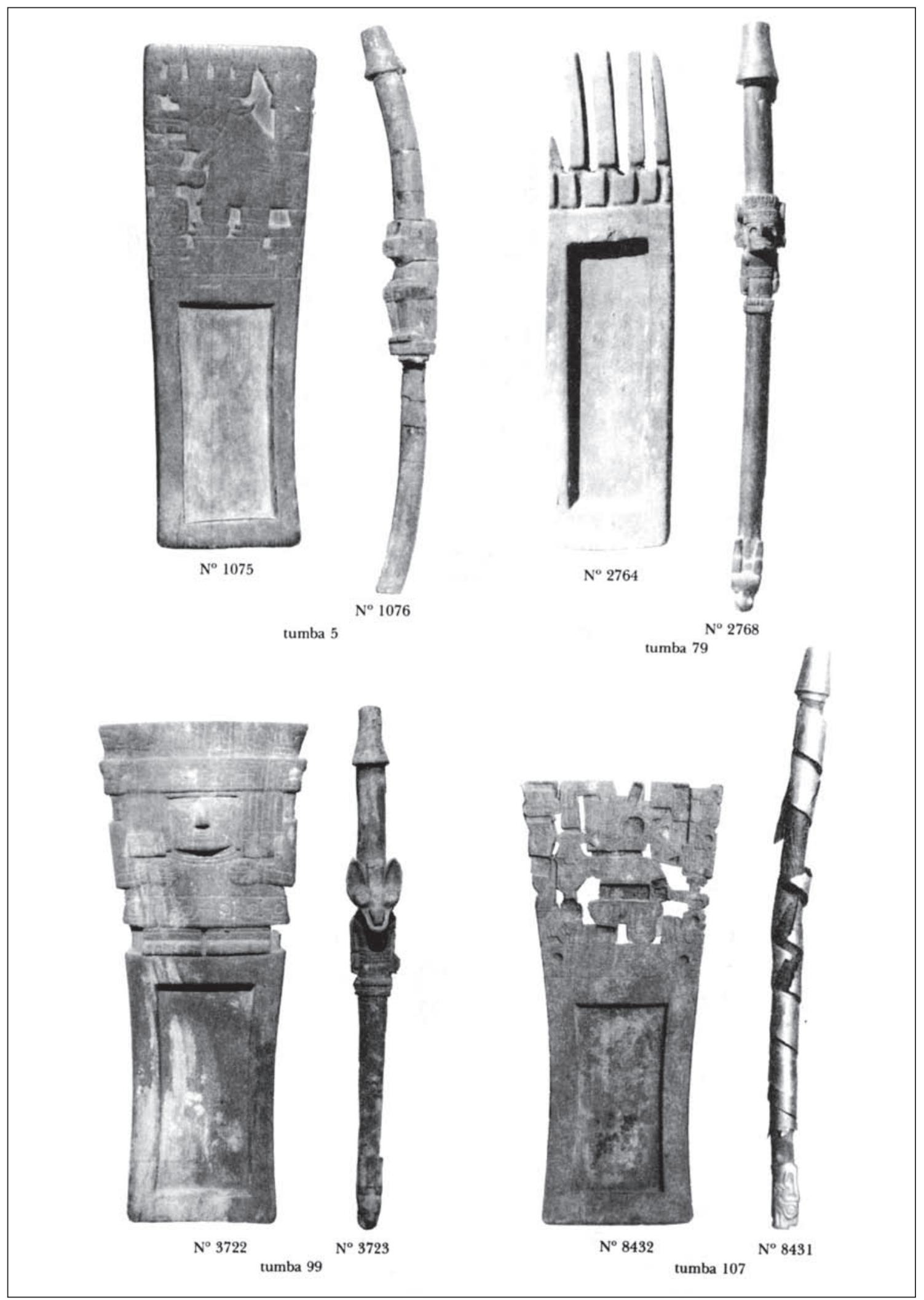

Figura 14. Asociaciones de tubos y tabletas de Solcor 3. 

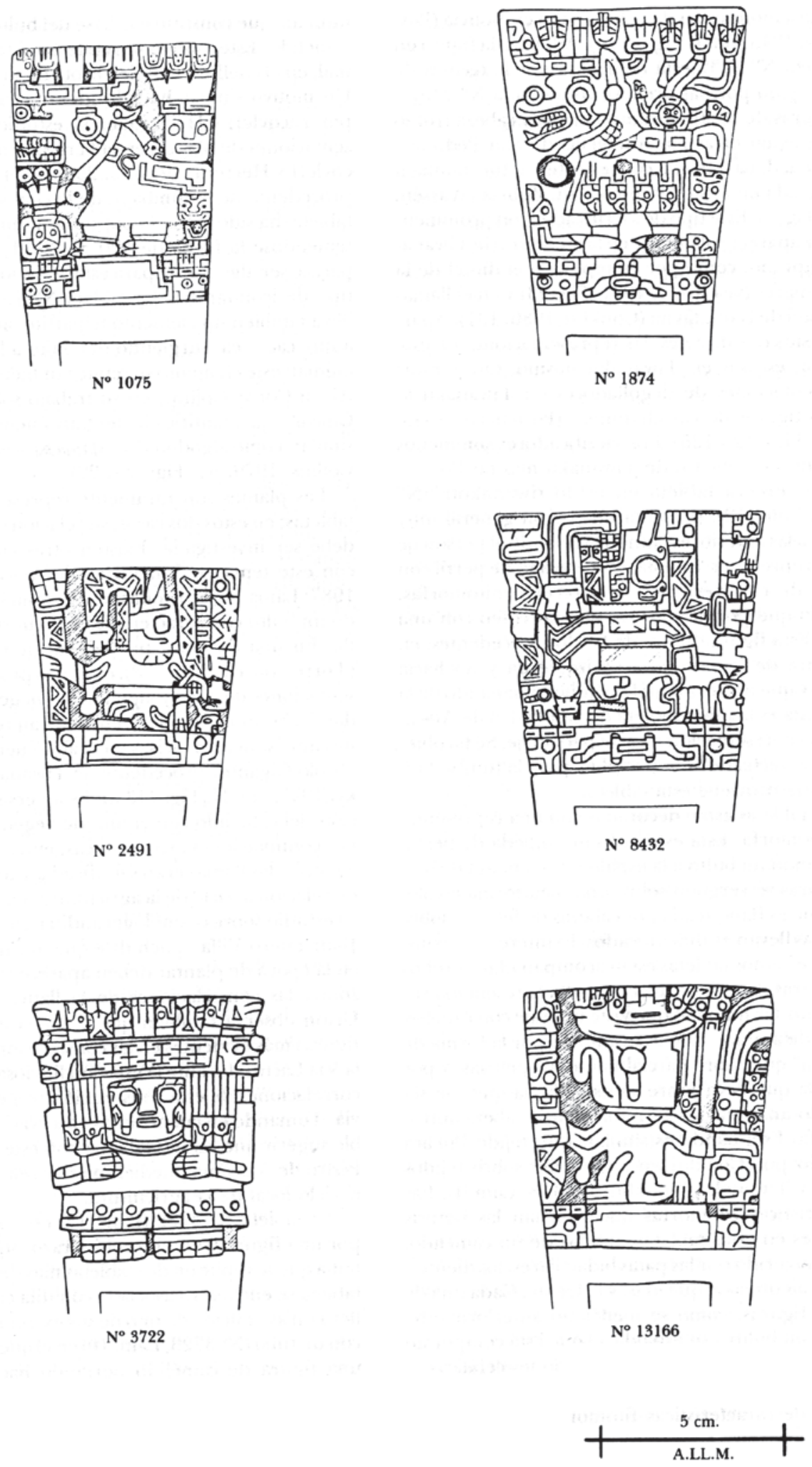

Figura 15. Iconografía de tabletas de la Fase B de Solcor 3. 
Figuras de perfil portando hacha y cabeza trofeo son vistas en otras cinco tabletas de San Pedro de Atacama. Una tableta con este tema fue también encontrada en el sitio Niño Korin, Bolivia (Wassén 1972: Fig. 5). Este tipo de sacrificador con prominente nariz aparece solamente en la escultura de Tiwanaku temprano, como por ejemplo, en el dintel de la calle Linares (Rowe 1971: Fig. 23) y en el llamado Dintel de Kantatayita (Conklin 1986: 131). Aparte de estos dos dinteles, las representaciones de este tipo son escasas en Tiwanaku mismo. Otras raras representaciones de degolladores en Tiwanaku lo son las figuras de Chachapumas (Posnansky 1945, vol. 2: Figs. 123-125). Los sacrificadores son menos frecuentes en objetos de Tiwanaku más tardío.

Una tercera tableta en estilo tiwanakota $\left(n^{\circ} 13166\right.$, Figura 15) presenta un patrón general muy similar a las anteriores, aunque variando el personaje que se representa. En ésta, una entidad de perfil con cabeza de características al parecer ornitomorfas, porta lo que podría ser una cabeza trofeo con una estela. Esta figura difiere de las dos precedentes, en que mira de frente hacia su izquierda y no hacia arriba, y que no lleva aquel apéndice emanando de la boca. Esta es la única tableta de San Pedro de Atacama con representación de este personaje. Se ha obtenido una fecha de $480 \pm 80$ DC para la tumba 117 , de donde proviene esta tableta.

Dos tabletas están decoradas con una representación zoomorfa. Esta es una figura bípeda de perfil, acarreando un bulto a la espalda. En ambas tabletas, las figuras se yerguen sobre una plataforma escalonada que es flanqueada por cabezas de felino y sobre sus testas llevan grandes tocados. Es interesante constatar que las dos tabletas están acompañadas de tubos con figuras de felinos. La creatura representada sugiere a un ser humano que viste un traje con características de animal. Esto es insinuado por la forma de la "falda" que cubre parcialmente sus piernas, y por la banda que lleva sobre su espalda, la que cae semejando una cola que termina en una cabeza antropomorfa. Esta banda es similar a un tejido Pukara ilustrado por Conklin en su estudio sobre tejidos Pukara y Tiwanaku (Conklin 1983: 8, Lám. I). Las características zoomorfas que exornan las figuras presentes en estas tabletas son las de un camélido. Esto es sugerido por las patas bidactilares, los dientes, la boca, las orejas arqueadas, y la frente. Cada una de las dos figuras, como se mencionó anteriormente, acarrea un bulto a su espalda, el que está compuesto por una cara humana con proyecciones cefálicas.
En la tableta $n^{\circ} 1075$ (Figura 15) surgen tres elementos de características fitomorfas, sobre la cara humana que constituye la base del bulto que porta el camélido. Este motivo se repite en el tocado del animal, en el cuello, y también brota de su talón trasero. Un motivo similar ha sido identificado como maíz por Yacovleff y Herrera, en su estudio sobre representaciones de plantas en el Perú precolombino (Yacovleff y Herrera 1934-35: 258, Fig. 4). Un ceramio procedente de la tumba 5 , de la cual se obtuvo esta tableta, ha sido fechado por termoluminiscencia,

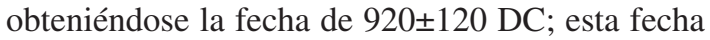
parece ser algo tardía para estar relacionada con este tipo de iconografía. La tableta $n^{\circ} 1874$ (Figura 15) lleva también un elemento tripartito, algo sugerente a una cactácea, surgiendo del bulto a la espalda del animal; este elemento se repite también en la corona. Cordy-Collins, en su trabajo sobre un tejido Chavín, ha identificado tentativamente un motivo similar, como algodón (Gossypium barbadense) (CordyCollins 1979: 51, Figs. 21, 22).

Las plantas son raramente representadas en las tabletas; en estos dos casos, su relación con camélidos debe ser investigada. Existen otras cuatro tabletas con este tema en San Pedro de Atacama (Torres 1987: Láms. 87, 88), todas con un camélido acarreando un bulto con características fitomorfas a la espalda. En una de éstas, procedente de Coyo Oriente (Torres 1987: Lám. 88), estas dos probables representaciones de maíz y algodón se encuentran asociadas. Debe anotarse que se encuentran representaciones muy similares incisas en el abdomen del llamado "Idolo Gigante" procedente de Tiwanaku (Posnansky 1945, vol. 2: Fig. 113a). Esta persistente asociación del camélido con el mundo vegetal pudiera tener connotaciones astronómicas; entre los incas, por ejemplo, las llamas eran sacrificadas a intervalos fijos en relación al ciclo de la agricultura. Urton (1981) en su estudio sobre cosmología andina cita al etnógrafo Tuero Villa, quien dice que durante las tardes en la época de plantar deben aparecer sobre el horizonte, las constelaciones de la llama y del arado. Urton observa también que la llama es una de las figuras más evidentes en las constelaciones negras de la vía láctea durante la estación lluviosa y encuentra correlaciones de esta constelación con el sol y la lluvia. Tomando en cuenta estas observaciones, es posible sugerir que las seis tabletas con este tema en San Pedro de Atacama pudieran estar relacionadas con el ciclo local de la agricultura. 
La tableta $n^{\circ} 3722$ (Figura 15) está ornamentada por una figura frontal con los brazos sobre el pecho, tema que se repite en dos tabletas más de la zona. Esta tableta se encuentra asociada con una cucharilla que lleva un ave tallada en uno de sus extremos y, además con un tubo ( $\mathrm{n}^{\circ} 3723$, ver Figura 13) en el que se ha tallado una figura de camélido portando hacha y cabeza trofeo. Existen varios tubos con similares representaciones de sacrificadores con cabeza de camélido (Torres 1987: Lám. 139), pero este tubo de Solcor 3 es el único con rasgos claramente tiwanakotas.

Todas las tabletas de Solcor 3 previamente mencionadas han tenido sus equivalentes entre las tabletas procedentes de otros sitios en el área de San Pedro de Atacama. Sin embargo, la tableta n ${ }^{\circ} 1112$ (Figura 16), de la tumba 6, es un caso único en la zona. Al centro de un panel grabado en estilo tiwanakota se levanta un felino tallado en bulto. Los grabados en la superficie del panel consisten en cuatro cabezas de felinos, motivo frecuente en la escultura Tiwanaku; pero en las dos esquinas superiores se encuentra un motivo compuesto por un círculo rodeado por círculos menores, que no aparece en ninguna otra tableta de este estilo en el área de San Pedro de Atacama. Esta tableta presenta cierta similitud con una de piedra procedente del sitio mismo de Tiwanaku en Bolivia (Wassén 1967: Fig. 30).

En Solcor 3 se han encontrado cinco tubos inhalatorios con manifiesto estilo tiwanakota, incluyendo el que se mencionó recién, con la representación del camélido sacrificador. Los cuatro tubos restantes ( ${ }^{\text {os }} 2647,2768,3766$ y 13167 , ver Figuras 12 y 13) llevan en la parte central una figura antropomorfa con los brazos extendidos a ambos lados del cuerpo, imitando las esculturas monolíticas de Tiwanaku. Existen otros 10 tubos en San Pedro de Atacama con esta misma representación; pero entre todos ellos, sólo uno de los de Solcor 3 lleva hacha y cabeza trofeo y una prominente nariz. La decoración presente en el extremo distal de estos tubos, o sea, la parte aplicada al polvo, es siempre una cabeza de camélido. Esta complementación iconográfica es bastante frecuente en San Pedro de Atacama, y parece ser un atributo asociado con Tiwanaku.

Además de las tabletas previamente mencionadas (las 12 con panel sin decoración y las ocho con iconografía tiwanakota), existen otras 14 tabletas procedentes del sitio en estudio, que llevan decoración, pero sin atributos típicamente tiwanakotas.
Entre éstas, cuatro llevan figuras humanas aparentemente posadas sobre el borde superior del recipiente, esculpidas en un estilo especial pero sencillo, sin las aplicaciones y atuendos observados anteriormente. En dos tabletas de este tipo ( ${ }^{\text {os }} 1668$ y 2046) (ver Figuras 10 y 16) llama la atención las amplias y rectangulares orejas de las figuras, así como los largos brazos que se apoyan en el suelo. En una tercera ( $\mathrm{n}^{\circ}$ 1989, ver Figura 10) el personaje lleva una cabeza en la mano izquierda y un objeto indefinido en la derecha. Una cuarta ( $n^{\circ} 2381$, Figura 16) muestra un personaje acuclillado con las manos aparentemente atadas a la espalda, dando la impresión de tratarse de un prisionero. La tableta $\mathrm{n}^{\mathrm{o}} 2117$ (Figura 16) lleva dos individuos de cuerpos rectangulares con facciones y ornamentación incisa, y, en la tableta $\mathrm{n}^{\mathrm{o}} 1573$ (Figura 10), la figura humana se ha querido representar utilizando el recipiente como el tronco del cuerpo.

En Solcor 3 hay sólo una tableta con representación zoomorfa que no corresponde al estilo tiwanakota. Esta tableta ( $\mathrm{n}^{\circ}$ 2207) lleva el cuerpo de un felino que se ubica paralelo al recipiente, pero por sobre su nivel; la cabeza mira hacia el recipiente, y las patas se flectan en ángulo recto, para unirse al borde de la caja. Otras tabletas de Solcor 3 llevan uno, dos o cinco apéndices en el lugar del panel. La de cinco apéndices ( $\mathrm{n}^{\circ} 2764$, Figura 14) pareciera representar la garra de un felino. Por último, y para terminar esta revisión iconográfica, no podemos dejar de mencionar las dos tabletas con diseños no figurativos ( $\mathrm{n}^{\text {os }} 1188$ y 1265 , Figuras 9 y 16), una con puntuaciones incisas y la otra con diseño grabado.

\section{Secuencia y asociaciones}

Los únicos dos tubos que se encuentran asociados con alfarería de la Fase A no presentan decoración en relieve. Uno de los dos ( ${ }^{\circ}$ 1113) lleva decoración pirograbada geométrica, y aunque se asocie con cerámica negra pulida, hay que hacer notar que está junto con la tableta $\mathrm{n}^{\circ} 1112$, de estilo Tiwanaku. En la Fase B, junto con tubos sencillos, se hacen presentes aquellos que muestran figuras esculpidas en volumen, predominando el clásico estilo tiwanaku. Aunque podría ponerse en duda si el estilo de algunas de estas expresiones artísticas es en verdad tiwanakota, hay dos tubos cuyas representaciones difieren francamente de él. Son los casos del lagarto del tubo $\mathrm{n}^{\circ} 8439$ (Figura 13) y las cabezas anatrópicas grabadas en el tubo $\mathrm{n}^{\circ} 8431$ (Figura 13). Lo que unifica los tubos decorados de la Fase B, a pesar 


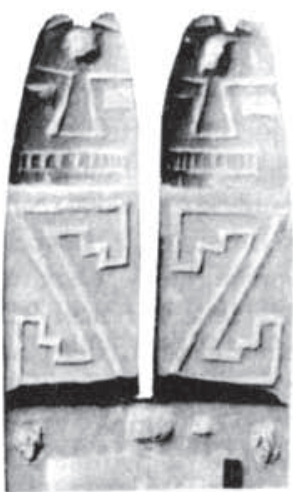

$N^{\circ} 2117$

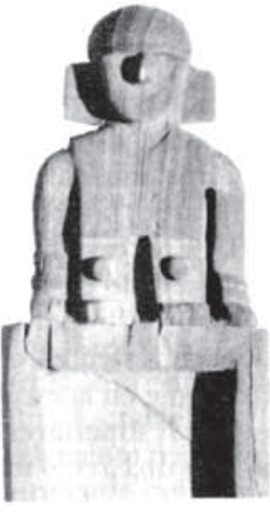

$N^{\circ} 1668$

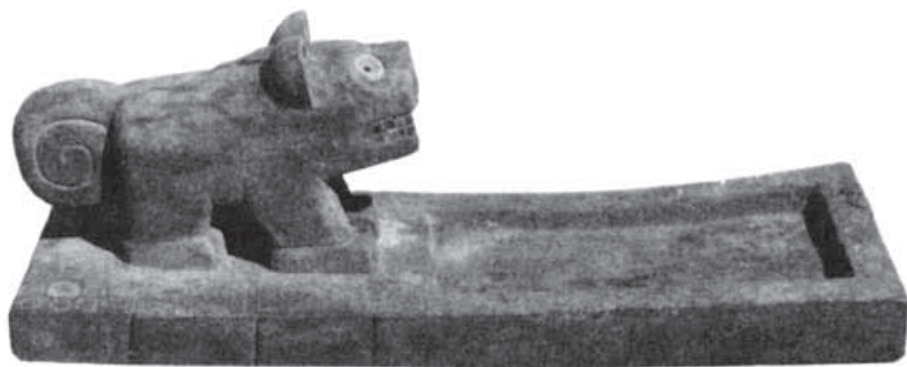

$\mathbf{N}^{\circ} 1112$

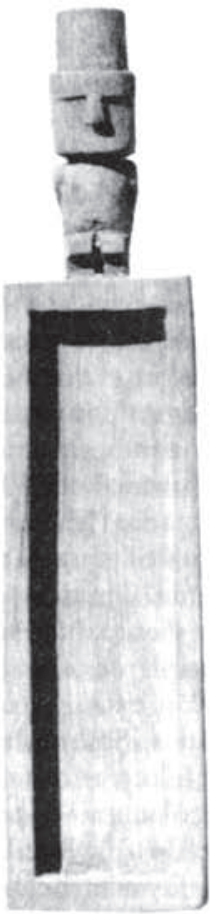

$\mathrm{N}^{\circ} 2381$
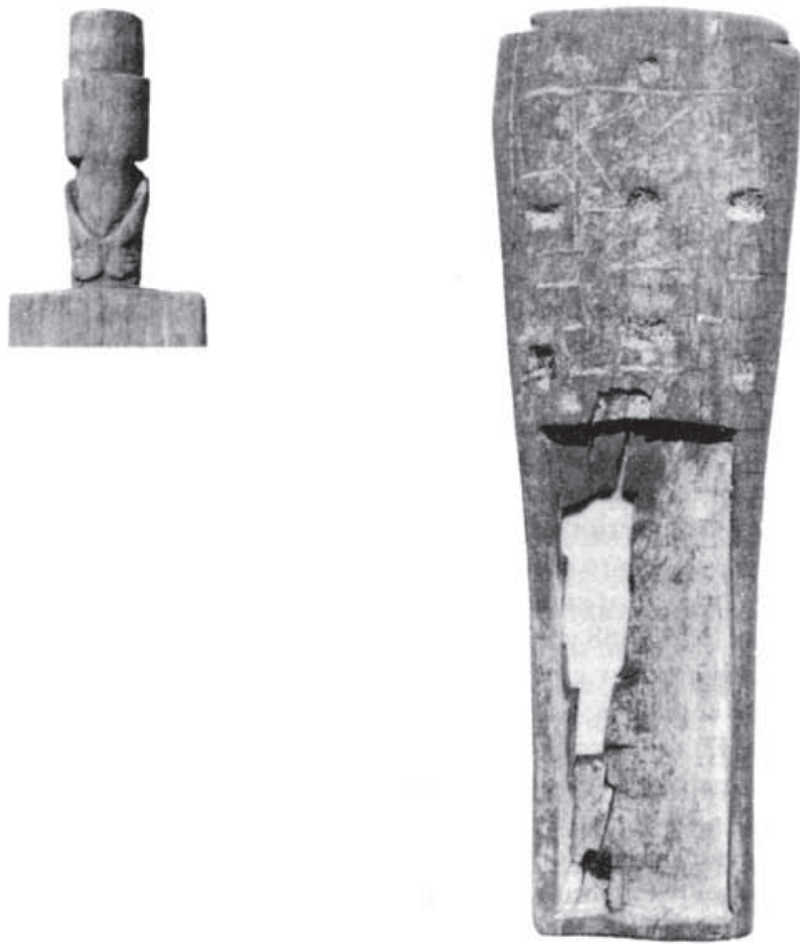

$\mathrm{N}^{\circ} 1265$

Figura 16. Iconografía de tabletas de la Fase B de Solcor 3. 
de la presencia de variados estilos, es la cabeza de camélido en el extremo distal.

En cuanto a las tabletas, sin duda el patrón predominante en la Fase A es el rectangular. Dentro de éste, las representaciones humanas en volumen son las más comunes y, como ya se indicó, no llevan atributos estilísticos tiwanakotas. La tableta con el personaje de manos atadas ( $\left.n^{\circ} 2381\right)$ parecería ser la más temprana dentro de la Fase A, o aún más, podría ser anterior a la misma, de acuerdo con el contexto ceramológico que la acompaña. La tableta $\mathrm{n}^{\circ} 1573$, en la que se usó el recipiente como tronco del cuerpo humano, es un patrón extraño, por lo que podría asumirse como foránea. Sólo se hace presente una figura zoomorfa (el felino en volumen de la tableta $n^{\circ}$ 2207). Aparecen solamente dos tabletas rectangulares con panel tableado (una de ellas con decoración puntiforme incisa). Hay cuatro tabletas que escapan del patrón rectangular predominante: una trapezoidal con apéndices $\left(\mathrm{n}^{\circ} 2518\right)$, una hiperbólica típica sin decorado $\left(\mathrm{n}^{\circ} 3038\right)$, una hiperbólica atípica ( $\left.{ }^{\circ} 1909\right)$, y una hiperbólica con felino en volumen con atributos tiwanakotas $\left(n^{\circ} 1112\right)$. Estas últimas cuatro tabletas aparecen como intrusivas en la Fase A, por presentar concepciones estéticas muy diferentes a las predominantes, aproximándose más a las de la Fase B.

En la Fase B el predominio de tabletas es del tipo hiperbólico. Dentro de este tipo se daría la misma proporción entre las tabletas decoradas y las no decoradas. En el caso de las decoradas, el estilo clásico de Tiwanaku es el más importante. Hay sólo una tableta hiperbólica con diseño no figurativo, difícil de identificar con el estilo tiwanakota (nº 1265). En las rectangulares, que también se hacen presentes en la Fase B, aunque en menor proporción, resalta el panel tableado, ya sea carente de decoración o con incrustaciones. Dos tabletas rectangulares muestran lados convexos y también hay una tableta trapezoidal $\left(n^{\circ} 3741\right)$ con lados convexos.

La tableta $\mathrm{n}^{\mathrm{o}} 1112$ correspondiente al felino tiwanakota tridimensional, considerada como de la Fase A, podría representar las primeras intrusiones intensivas de la cultura altiplánica en San Pedro de Atacama. La tableta $n^{\circ} 1989$ que tiene una figura humana voluminosa, se diferencia de las que podríamos definir como de estilo atacameño (Fase A) por llevar una cabeza en una mano; además, se asocia con un tubo con figura de cóndor en el estilo Tiwanaku. Esto nos hace pensar que la tumba 50 que contiene la tableta y el tubo recién referidos podría corresponder a una tumba de transición o inicial de la Fase B. Por otro lado, el personaje flectado, de nariz prominente de las tabletas $\mathrm{n}^{\text {os }} 2491$ y 8432 , se ha identificado como elemento propio del Período Tiwanaku Temprano, de acuerdo con el esquema de Bennett. Sin embargo, el único personaje tiwanakota en Solcor 3 que tenemos datado con fecha temprana ( $480 \pm 80 \mathrm{DC})$, es el de la tableta $\mathrm{n}^{\circ} 13166$ que, al parecer, representa una falcónida de impronta estilística similar a las anteriores. También tenemos una fecha para el camélido que porta un bulto a su espalda, pero como se dijo, parece ser demasiado tardía para estar relacionada con este tipo de iconografía (920 \pm 120 DC). Sin embargo, pensamos que aunque la fecha no fuera correcta, de todas maneras podría corresponder a los últimos personajes de la cosmología tiwanakota. Es interesante observar que las dos tabletas que llevan inserto este personaje zoomorfo ocupan los dos extremos en cuanto al índice que señala la ubicación del acinturamiento en las tabletas hiperbólicas (1.2 y 1.5), lo que las distanciaría del promedio de las más típicas tabletas tiwanakotas.

Al revisar las asociaciones entre tabletas y tubos, llama la atención la falta de cohesión estilística entre estos dos elementos del complejo alucinógeno. Es así como se registran dos casos de asociación entre un tubo sencillo y una tableta no decorada, cinco tubos sencillos con tabletas decoradas, y ocho casos de tubos decorados con tabletas decoradas (Figura 14). El cruce de asociaciones entre ambos objetos puede darse de igual forma con ausencia de decorado, con decorado tiwanakota o con decorado no tiwanakota; la única asociación que no se verifica es la de tubo decorado con tableta no decorada.

\section{Composición de las unidades funerarias}

A nivel general se observa que prácticamente la mitad de las tumbas contiene un solo cuerpo, y la otra mitad corresponde a tumbas múltiples que van de dos hasta 12 individuos. En la Fase B esta proporción se mantiene y en la Fase A se observa que las tumbas individuales representan un porcentaje mayor $(65 \%)$. De acuerdo con los registros, el $26 \%$ de la población de Solcor 3 se encontró en tumbas individuales y el $74 \%$ en tumbas múltiples. Estos porcentajes, con moderadas variaciones, se mantienen en cada una de las dos fases culturales que estamos estudiando. Las tumbas múltiples en la Fase A son notoriamente poco numerosas en sus respectivas categorías, predominando las de dos, tres 
y cuatro individuos $(7,10$ y $7 \%$, respectivamente); le siguen tumbas de 8,10 y 12 individuos, con un caso cada una (3\% por cada caso). En la Fase B, las tumbas múltiples disminuyen mientras mayor sea la cantidad de cuerpos que contiene: $24 \%$ con dos cuerpos, $12 \%$ con tres, $6 \%$ con cuatro y $3 \%$ con cinco y seis individuos. Hay que hacer notar que en la Fase B las tumbas dobles equivalen prácticamente a la mitad de las individuales, y a su vez, al doble de las múltiples de más de dos cuerpos; también es notorio el hecho de que en esta fase no hay tumbas de más de seis cuerpos. Al comparar las tumbas de los portadores de objetos psicotrópicos con las que carecen de dichos implementos, observamos lo siguiente. En la Fase A, las tumbas individuales sin tabletas superan a las con tabletas: $77 \%$ en las primeras y $50 \%$ en las segundas; en cambio, las tumbas con tabletas y tres cuerpos muestran un porcentaje alto en relación a su propio grupo (30\%), y con mayor razón en relación al grupo sin tabletas, ya que éste no tiene tumbas triples. Resalta también el hecho de que la tumba de mayor número de cuerpos de la Fase A (12 cuerpos) registra tabletas; sin embargo, creemos que este hecho es casual ya que se trata de una tumba disturbada en el pasado. En general, las tumbas numerosas son tumbas alteradas, como las de ocho, cuatro y aun de tres cuerpos. Ante esta última observación, resulta que la única tumba múltiple de la Fase A no disturbada podría ser la tumba 6, que tiene tres cuerpos; pero incluso ésta merece dudas, ya que la posición semirrecostada de los cuerpos resulta atípica en el contexto del cementerio. Se concluye entonces que la modalidad preferente de enterratorios fueron las tumbas individuales, con una frecuencia menor de tumbas dobles. Los entierros colectivos son el resultado de la reocupación de los mismos espacios para enterrar uno o dos individuos, por veces donde ya habían otros, sin que necesariamente la proximidad física implique nexos directos entre los múltiples cuerpos. Esto se constata en el hecho de que en varias tumbas múltiples el cuerpo intacto pertenece a la Fase B, y los disturbados que están junto a él, a la Fase A (p.e., tumbas 68, 70, 76).

En la Fase B, en las diferentes categorías de tumbas, no hay muchas diferencias de porcentajes entre portadores y no portadores; la diferencia más notoria se da en la categoría de enterratorios individuales, donde se observa un $10 \%$ más en favor de los no portadores, y algo similar ocurre con las tumbas dobles, pero esta vez favoreciendo a los portadores. Estas diferencias no son lo suficientemente notorias como para alterar la apreciación de que, en cuanto a composición numérica de las tumbas, los portadores y no portadores de la Fase B se comportan bajo el mismo patrón.

Para llevar a cabo un análisis de la composición sexual de los enterratorios, se reunieron en una sola muestra las 47 tumbas de las Fases A y B, para las cuales fue posible diagnosticar el sexo de todos sus miembros. En primer lugar, se pudo determinar que las tumbas individuales, que como se vio anteriormente corresponden a la tendencia generalizada, pueden albergar hombres, mujeres o niños. Predominan en todo caso las tumbas de hombres, le siguen las de mujeres y por último las de niños. Además, quedó en claro que la mayoría de las mujeres y de los niños de tumbas individuales no llevan implementos psicotrópicos. En los enterratorios dobles, que son los que siguen en popularidad, se trata preferentemente de un hombre y una mujer; hay excepciones en que se hacen presentes dos hombres o dos mujeres, pero en estos casos se trata de tumbas en que uno de los cuerpos se alteró al enterrar el otro; también se registra un confuso entierro de dos niños. En la Fase A las tumbas de parejas presentan un porcentaje mayor en los portadores que en los no portadores; en cambio, en la Fase B las proporciones se presentan compartidas por igual entre ambos sexos. Las tumbas triples no son claras; al menos una de ellas debe ser considerada como tumba doble hombre/mujer, ya que el tercer cuerpo (masculino) estaba disturbado. Otra tendencia que es necesario anotar es la presencia de hombres asociados con niños, y no tanto mujeres con niños que es lo que, por lógica, se esperaría. Hay más hombres enterrados junto con niños en la Fase A que en la Fase B, favoreciendo en ese caso a los entierros que no llevan objetos inhalatorios. En las tumbas múltiples, la cantidad de individuos que aparecen asociados con tabletas es prácticamente la misma que en las tumbas donde no hay de estos elementos. En las demás combinaciones presentes en Solcor 3, no se observa ninguna distribución sexual que pueda ser considerada como prerrogativa de algún grupo en especial.

\section{Atributos antropofísicos de los portadores}

En un primer análisis se puede constatar que en las dos fases culturales hay mayoría de varones como portadores o formando parte de tumbas con elementos psicotrópicos; el $72 \%$ de los varones de Solcor 3 está en esta condición. La proporción de mujeres portadoras o en tumbas de portadores es mucho menor (47\%). En las tumbas individuales, 
los hombres portadores superan a las mujeres portadoras con una cifra de 88\%; esto en la Fase B, ya que en la Fase A no se registran mujeres portadoras. Entre los no portadores de objetos psicotrópicos, la relación entre hombres y mujeres es proporcional en ambas fases. De acuerdo a estos datos, son los varones los que están más directamente relacionados con la psicotropía.

La proporción en la Fase A de niños asociados a tumbas con objetos para inhalar alucinógenos, $\mathrm{y}$ niños sin tales elementos, es similar; en cambio, en la Fase B, los niños sin asociación con la esfera psicotrópica duplican a los otros. En las tumbas individuales no se registra ningún niño asociado directamente con objetos inhalatorios, excepto el de la tumba 44 (ver Figura 1) que, por su contexto, no se puede asociar a ninguna de las dos fases culturales analizadas (aunque por el estilo de la tableta se podría asignar a la Fase B).

La asociación de las edades de los individuos con las prácticas inhalatorias no está claramente definida, mejor dicho, parecería no haber una distinción muy estricta para ello. El promedio de edad para los hombres portadores es de 30-35 años. El modo de las edades para los varones portadores coincide con el promedio, en cambio, para los no portadores es más bajo (25-30 años). La edad máxima de los varones portadores y no portadores es de 45-50 años; excepto entre los portadores de la Fase B donde se registra 35-40 años como edad máxima. Por su parte, la edad mínima se fijaría en 25-30 años, con excepción de los portadores de la Fase B donde baja a 20-25 años. En relación a mujeres portadoras sólo se registra un caso en cada fase, coincidiendo ambas con una edad de 45-50 años. Esta edad resulta ser, en las mujeres, la más longeva, y no se encuentran casos con esa edad entre las mujeres no portadoras. En resumen, se podría decir que entre los hombres, la edad mínima para tener acceso a las prácticas alucinógenas era de 25-30 años en la Fase A, y de 20-25 años en la Fase B. En cambio, las pocas mujeres que podían tener acceso a dichas prácticas debían ser las más ancianas del grupo.

Otro de los aspectos antropofísicos que hemos puesto en análisis ha sido la deformación craneana, con el afán de encontrar algún indicador inter o intraétnico que permitiera una mejor caracterización de los individuos portadores de objetos inhalatorios. Para llevar a cabo este análisis nos hemos restringido solamente a las tumbas individuales, asegurándonos así, la directa relación entre la deformación y el portador o no portador de tabletas o tubos, dando al mismo tiempo, la posibilidad de incorporar la variable sexo con la misma seguridad.

Según los gráficos de sectores (Gráficos 1 y 2), se observa que en la Fase A no hay diferencias significativas entre los diversos tipos de deformaciones al comparar el grupo de portadores y el grupo de no portadores de objetos psicotrópicos. Esto queda confirmado por la prueba de bondad de ajuste, la que da un $61.87 \%$ de confianza para esta afirmación. En cambio, en la Fase B se observan diferencias significativas, especialmente en relación a la distribución de la deformación fronto-lambdoidal entre los no deformados (Gráficos 3 y 4). Estas diferencias son corroboradas con un $99.79 \%$ de seguridad dada por la misma prueba anterior. Llama la atención que la distribución de las deformaciones entre los portadores de la Fase B es similar a la distribución general de la Fase A (compárese Gráfico 4 con Gráficos 1 y 2). En consecuencia, son los individuos no portadores de la Fase B los que gravitan en la disimilitud del universo analizado. ${ }^{9}$

Pensando que el sexo pudiera tener alguna implicancia en los resultados obtenidos, hemos implementado la base de datos con el registro sexual. La nueva información no dio diferencias significativas en la Fase A, obteniéndose sólo un $61.87 \%$ de confianza para decir que las distribuciones son diferentes. En la Fase B, la diferenciación sexual arrojó un $73.85 \%$ de confianza para pensar que la distribución de las deformaciones es diferente entre hombres y mujeres; sin embargo, no es un porcentaje suficiente para afirmarlo con seguridad.

Como una forma de buscar mayor claridad a este respecto, procedimos a comparar hombres portadores con hombres no portadores, y lo mismo, entre mujeres. Dado que en relación a varones sin implementos inhalatorios en la Fase B tenemos sólo un caso, hemos centrado nuestro análisis exclusivamente en las mujeres, obteniendo de esta contrastación un $55.52 \%$ en la prueba de bondad de ajuste, lo que nos acerca más a una igualdad que a una diferencia. En consecuencia, si en el estamento femenino no se acusa diferencia, quiere decir que la diferencia referida anteriormente la está dando el estamento

9 Este análisis fue realizado por Raúl Zhigley, del Departamento de Matemáticas de la Universidad del Norte, Antofagasta. 
masculino. Podemos pensar entonces, que el patrón de deformación en relación al sexo no varía entre portadores y no portadores de la Fase B; lo que hace la diferencia observada entre unos y otros es la mayor concentración de varones entre los portadores de esta fase (esto nos lleva al mismo tiempo a asumir la existencia de una diferenciación sexual en relación a las deformaciones craneanas).

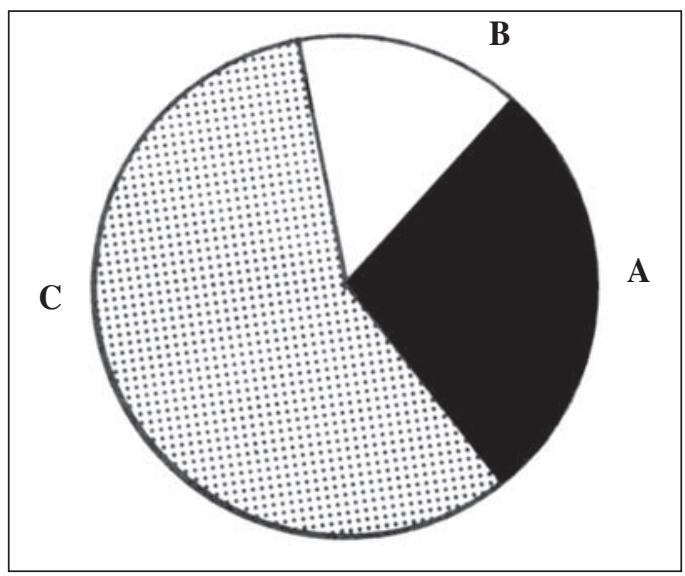

Gráfico 1. Fase A: No portadores.

A. Fronto-occipital: 28.57

B. Fronto-lambdoidal: 14.29

C. Sin deformación: 57.14

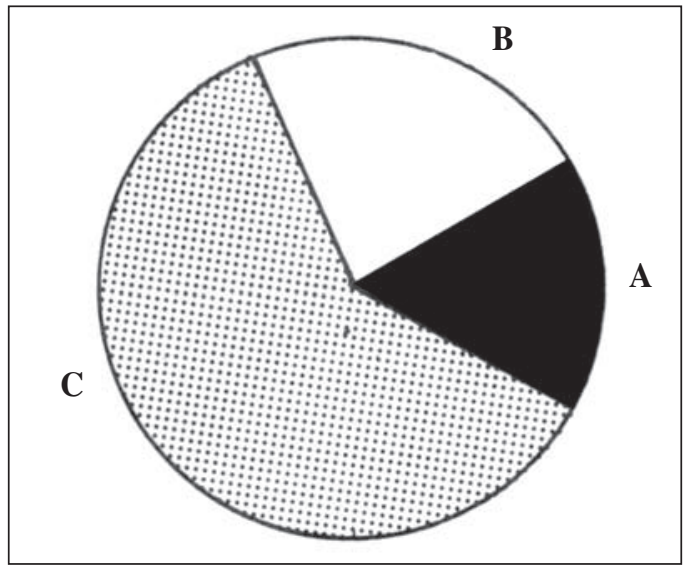

Gráfico 2. Fase A: Portadores.
A. Fronto-occipital: 16.67
B. Fronto-lambdoidal: 22.22
C. Sin deformación: 61.11

Otro indicador que usamos para detectar las relaciones inter o intraétnicas de los portadores, esta vez a nivel de afinidad biológica, fueron los rasgos discontinuos. Para esta indagación se utilizaron exclusivamente las tumbas individuales, y los análisis estadísticos se llevaron a cabo segregando el sexo en el interior de los grupos, a manera de lograr inferir aspectos endo o exogámicos que comprometieran a los portadores de elementos psicotrópicos. Los resultados del análisis del Promedio de Medidas de Divergencia señalaron que el grupo de portadores de la Fase A y el grupo de no portadores de la misma fase son muy parecidos entre sí. Lo mismo se constató al hacer similar comparación dentro de la Fase B. A su vez, la comparación entre las dos fases no aportó diferencias notorias, aunque la distancia obtenida entre los portadores de ambas fases fue mayor que entre portadores y no portadores dentro de cada fase (.03).

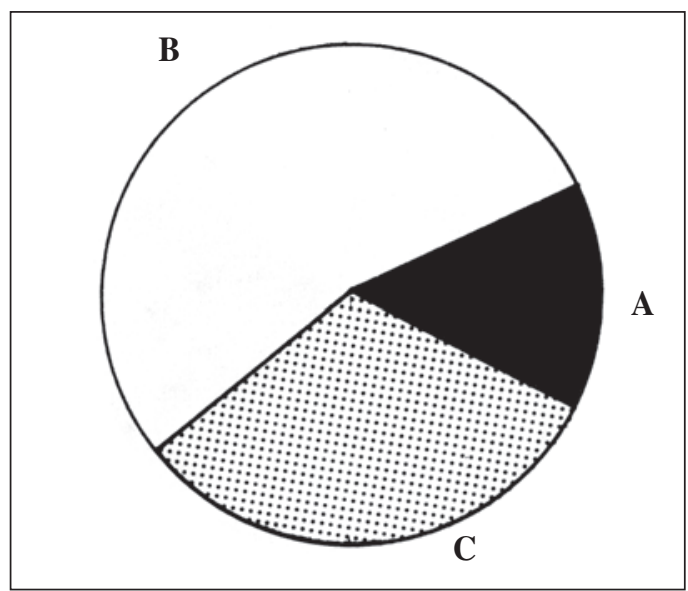

Gráfico 3. Fase B: No portadores.

A. Fronto-occipital: 15.38

B. Fronto-lambdoidal: 53.85

C. Sin deformación: 30.77

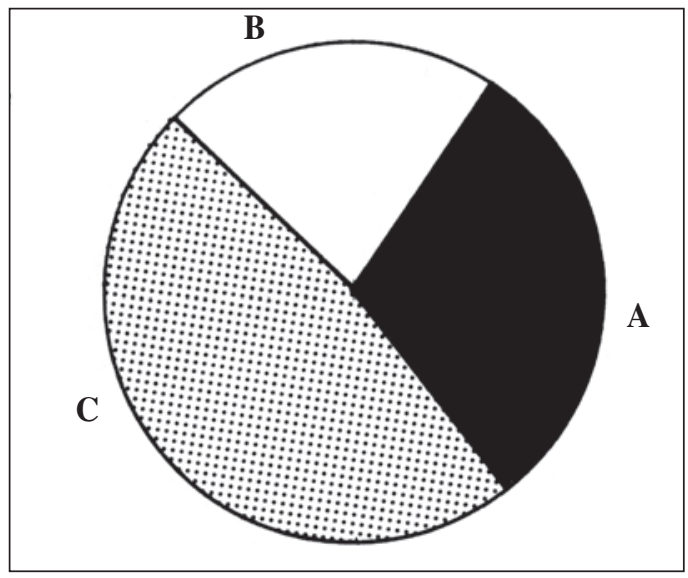

Gráfico 4. Fase B: Portadores.

A. Fronto-occipital: 31.58

B. Fronto-lambdoidal: 21.05

C. Sin deformación: 47.37 
Cuando se comparan los grupos dentro de cada fase, los resultados del test de $\mathrm{X}^{2}$ de Sanghvi son más concordantes con los del Promedio de Medidas de Divergencia, en el análisis de los 15 rasgos que en el de los 21. ${ }^{10}$ En cambio, cuando se comparan las dos fases entre sí, el test de $\mathrm{X}^{2}$ es concordante con el Promedio de Medidas de Divergencia, con cualquiera de los dos grupos de rasgos que se utilice. Aplicando el Promedio de Medidas de Divergencia implementado con segregación sexual, la mayor distancia genética se observa al comparar los portadores de ambas fases, distancia ésta que afecta más a los hombres que a las mujeres. Con el $\mathrm{X}^{2}$, los resultados del análisis inter e intrafases no presenta mayores diferencias entre hombres y mujeres. La diferencia de resultados al usar los distintos métodos analíticos puede deberse a varios factores, entre ellos el tamaño de la muestra, que en nuestro caso es muy pequeña y, mucho más, en relación a las poquísimas mujeres portadoras. El Promedio de Medidas de Divergencia es muy sensible al tamaño de la muestra, mientras que el $\mathrm{X}^{2}$ de Sanghvi responde, no al tamaño, sino a las diferencias de frecuencia de los rasgos entre las muestras. Si la muestra es pequeña, aunque hubiesen muchas diferencias entre las frecuencias, el Promedio de Medidas de Divergencia no sería necesariamente muy grande; por lo mismo, en este caso, sería más creíble que el $\mathrm{X}^{2}$ de Sanghvi. Hay que recalcar que en el análisis de los 15 rasgos, los resultados por ambos métodos son muy similares, tanto para la comparación intrafase, como interfase. En conclusión, se podría decir que las poblaciones tienden a diferir a través del tiempo, habiendo una mayor distancia entre hombres que entre mujeres, ya que tanto el Promedio de Medidas de Divergencia como el $\mathrm{X}^{2}$ de Sanghvi muestran las diferencias más grandes cuando los otros grupos son comparados con éste.

10 Serie de 15 rasgos: Se ha considerado la presencia de surcos del frontal, incisura/agujero frontal, hueso incisura parietal, hueso astérico, agujero emisario esfenoidal, agujero timpánico marginal, hueso lambdático, hueso occípito-mastoídeo, hueso sutura sagital, arco milohioídeo, agujero supraorbital completo, agujero espinoso abierto, canal hipogloso doble, y ausencia de agujero cigomático facial.

Serie de 21 rasgos: A los anteriores se le agregó la presencia de: agujero etmoidal anterior exsutural, agujero infraorbitario accesorio, agujero palatino menor accesorio, hueso sutura lambdoidal, hueso sutura coronal, y canal condilar patente.

\section{Discusión}

El punto de partida de nuestra discusión debe referirse naturalmente al problema de que si es lícito o no identificar como chamanes a los atacameños portadores de objetos psicotrópicos.

Desde nuestro punto de vista hay varias características en las tabletas de Solcor 3 que se relacionan con el chamanismo. Varias tabletas de la Fase B con iconografía tiwanakota presentan figuras humanas que llevan marcas en los antebrazos y en las piernas, que podrían ser interpretadas como insinuación de huesos. La esqueletonización, tanto como el llamado estilo de rayos $\mathrm{X}$, son fenómenos comunes en el arte chamánico. Por otro lado, muchas figuras de las tabletas son de animales o llevan atributos de ellos; es así, que podemos ver figuras con características de felinos, de camélidos y de aves. El proceso psicoactivo de transformación en animal es uno de los fenómenos más comunes en el repertorio de los misterios chamánicos (Halifax 1982: 78-79).

La relación de felinos con el uso de alucinógenos es una de las asociaciones más frecuentes y está íntimamente relacionada con el chamanismo a través de las Américas (p.e., Reichel-Dolmatoff 1978: 52). Entre grupos actuales de El Chaco, se describe la manera en que un hechicero, al grito de "soy un jaguar", se lanzaba sobre su enemigo como hacen los jaguares; algunas personas, incluso, afirmaban que ya sus uñas se habían convertido en garras (Métraux 1944: 303). De la región andina se dice que el chamán, al llegar a los lugares solitarios del camino, se imaginaba que él era el propio espíritu animal que iba ascendiendo hacia la cordillera; lanzaba por esto, de tiempo en tiempo, bramidos o rugidos imitando a los felinos (Tello 1923: 188). La relación más directa, entre los casos etnográficos, es la de los kaxúyana; entre ellos, la tableta es llamada, en lengua caribe, yarákukúru, o imagen del jaguar mitológico del fondo del agua (Frikel 1961: 31).

González (1974) llevó a cabo un amplio análisis de la iconografía arqueológica del noroeste argentino, especialmente felínica, comparándola con homologías etnográficas sudamericanas y asimilándola con la esfera chamánica. Además de ello, debemos agregar que las representaciones de felinos han aparecido en una tableta arqueológica procedente de Tiwanaku (Wassén 1967: Fig. 30), en otra de Niño Korín en Bolivia (Wassén 1972: Fig. 5), en varias tabletas 
de oro encontradas en el área Muisca de Colombia (Torres 1987: Láms. 4 y 7), y en tabletas de otras áreas, del norte de Chile y del noroeste de Argentina (Torres 1987: Láms. 35 y 148). De acuerdo con Reichel-Dolmatoff (1978) los payé, o chamanes tukanos, inhalan un polvo psicoactivo preparado con la resina de la virola (Virola sp.) para establecer contacto con lo sobrenatural. En el trance así producido, el chamán obtiene información sobre la causa y el tratamiento de las enfermedades, o dónde hay caza o pesca. También nos dice el mismo autor, que a veces los chamanes toman grandes dosis de alucinógeno para transformarse en jaguares (Reichel-Dolmatoff 1978: 113). En San Pedro de Atacama, además de la transformación en felino, se pudiera añadir la transformación en camélido, animal representado en varias tabletas del área. El camélido, como fue mencionado previamente, tiene connotaciones astronómicas relacionadas con la manipulación de la agricultura y del clima.

Consecuentemente entonces, existe suficiente evidencia para sugerir que, al menos ciertas tabletas de San Pedro de Atacama, hayan sido utilizadas por personajes diestros en viajar al mundo sobrenatural y en comunicarse con los espíritus, con el propósito de recibir instrucciones para el apropiado funcionamiento de la sociedad. El chamanismo es el fenómeno que nos provee la mayor cantidad de indicaciones para comprender algunos aspectos de la iconografía expresada en la parafernalia inhalatoria, lo que a su vez nos permite entender algunos aspectos del pasado del chamanismo. De este modo se aclaran situaciones en las tabletas y en los tubos, como la de los individuos transformados en felinos, aves, o camélidos; la representación de huesos en los brazos y las piernas es otra de estas posibilidades. La adquisición de un estado extático y la subsecuente capacidad de comunicarse y viajar a otros mundos es la función primaria del complejo de objetos inhalatorios; capacidades éstas, asociadas al chamanismo, donde quiera que éste aparezca.

La relación entre estatus y chamanismo no es ajena a las poblaciones aborígenes cercanas a nuestra región. Elíade (1976) observa que el chamán disfruta de un prestigio y de una autoridad considerables entre los pueblos sudamericanos. Unicamente los chamanes pueden enriquecerse, esto es, almacenar cuchillos, peines, hachas, etc. Agrega el mencionado autor que es gracias a sus capacidades extáticas, más que a sus prestigios de magos, a las que el chamán sudamericano debe su posición mágico- religiosa y su autoridad social. Porque semejantes capacidades extáticas le permiten, además de su prerrogativa habitual de curandero, emprender viajes místicos al "cielo" para encontrarse cara a cara con los dioses y transmitirles las "oraciones" de los hombres.

Métraux (1944), al referirse a los indígenas de El Chaco, dice que la influencia de los chamanes sobre la comunidad era considerable y en algunos casos eran realmente los jefes del grupo. Los abipones consideraban un crimen, el contradecir sus palabras o el oponerse a sus deseos o mandatos, y temían su venganza. Los chamanes también obtenían ventajas sustanciales de su profesión: después de una expedición, esos mismos Abipones adjudicaban al chamán que los había acompañado, la mejor parte del botín, lo que hacía que éste dispusiera de enseres domésticos superiores a los del resto del grupo. Respecto a los chiriguanos, el mismo autor (Métraux Ms) señala que el origen de los jefes eran los hombres distinguidos por su coraje, elocuencia y, a menudo, por su poder mágico. Disfrutaban de un considerable prestigio y poseían no poco poder.

A pesar de la distancia en el tiempo, creemos que la evidencia arqueológica está corroborando una situación comparativa con estos ejemplos, en cuanto a relación entre prestigio y chamanismo entre los atacameños. En la Fase B, los ajuares más ricos, en cuanto a cantidad de objetos, corresponden a los portadores de tabletas. Tenemos una relación de 2.5 piezas promedio de cerámica por individuo, contra 1.3 piezas promedio en el grupo no portador; es decir, hay una diferencia de 1.2 piezas a favor del grupo de chamanes. Pero lo interesante es que en la Fase A no se observa este desbalance entre portadores y no portadores; lo que significa que en esta fase los chamanes no tenían más prestigio que los demás miembros de la sociedad. Es más, la cifra de 2.4 piezas de los portadores contra 3.2 de los no portadores señala que los chamanes podrían tener un estatus aún más bajo que el resto de la población de la Fase A. Con estos datos estaríamos frente a un hecho significativo en el proceso de cambio que va del momento pretiwanaku a aquél con franca influencia altiplánica. En los momentos previos, tendríamos una sociedad igualitaria o, al menos, en que la jefatura no iba por la línea de los hombresmedicina; posteriormente, la articulación de los atacameños con el fenómeno Tiwanaku incentivó la importancia de los chamanes, favoreciendo su prestigio y su poder. 
La iconografía de los objetos psicotrópicos muestra también cambios dignos de ser analizados. Como hemos visto al tratar de la secuencia en las formas, estilos e iconografía de las tabletas, los cambios entre la Fase A y la Fase B son notorios. Se produce la penetración de una concepción artística foránea para representar personajes mitológicos extraños a la cosmovisión atacameña; es decir, se importan in totum los personajes y su forma de representarlos. El hecho de que en Solcor 3 no hayan formas de transición en los estilos y/o iconografía, entre una y otra fase, nos plantea la posibilidad de que el cambio haya sido brusco, o que la fase de transición debería encontrarse en otro(s) sitio(s). De cualquier manera, se advierte que se logró imponer una nueva ideología con sus formas propias de expresión y representación.

Las tabletas atacameñas anteriores a la influencia tiwanakota enseñan una imaginería cosmológica naturalista, tanto para las figuras humanas como para las zoomorfas, a lo que habría que agregar una sobria sencillez. En cambio, las imágenes tiwanakotas traen a San Pedro de Atacama una pomposidad no conocida anteriormente; los cetros, las coronas y los atavíos de las entidades exógenas son emblemas de prestigio. Esa nueva ideología inculca también nuevas consideraciones sociales como es el concepto de estatus; concepto que, lógicamente, fue entendido y asumido por aquéllos que manejaban las ideas de la sociedad atacameña: los chamanes.

Sin embargo, a pesar del estatus alcanzado por los chamanes en la Fase B, éstos no llegaron a una especialización que los desligara de otras funciones. Sus ajuares no difieren cualitativamente de aquellos de los no portadores de tabletas. En el caso de los varones, vemos que llevan arcos, hachas y/o mazas, vinculándolos, al igual que los demás hombres del grupo, con actividades bélicas y cinegéticas. Pero si bien es cierto que el arco aparece como un arma común asociada a los varones, es interesante considerar lo que sucede con el hacha. En primer lugar debemos señalar que las hachas son menos numerosas que los arcos (se da una proporción aproximada de 2:3); luego, debemos analizar el comportamiento de estos instrumentos en relación a los portadores y no portadores de implementos psicotrópicos, en las dos fases estudiadas. Las hachas son más frecuentes a nivel general, entre los portadores; en la Fase A se da una relación de $40 \%$ contra $33 \%$ de los no portadores; mientras que en la Fase B tenemos una relación de $70 \%$ para los portadores y de $20 \%$ para los no portadores. Los datos dejan en evidencia que el desbalance en la Fase A no es tan acentuado como en la Fase B. Esta situación podría indicarnos que el hacha en la Fase B, tal vez adquirió un simbolismo de estatus o de poder, y es por eso que se hizo tan persistente en manos de la nueva estirpe de chamanes.

El hecho de que las edades de los varones con ajuar inhalatorio sean coincidentes con las de aquellos que carecen de dichos implementos, indicaría que la edad no es requisito selectivo para la investidura de chamán. El sexo, en cambio, tiene una importancia sustancial, como lo demuestra el hecho de que sólo dos de 13 individuos sexados, y de segura asociación con objetos psicotrópicos, sean mujeres. Al respecto, volvemos a recurrir al dato etnográfico. Métraux (1944) nos dice que en la mayoría de los pueblos chaqueños, las mujeres viejas tienen conocimientos medicinales y conocen también hechizos y danzas; pero en general, los chamanes verdaderos son hombres. La similitud de lo expuesto por Métraux se acentúa cuando observamos que las dos únicas mujeres de la esfera psicotrópica de Solcor 3 tienen 45-50 años. Una lleva una tableta muy sencilla, con panel sin decorar, y la otra, sólo un tubo simple. Hay ocho mujeres enterradas en tumbas individuales, de las cuales seis tienen edad de 40-45 años, sin objetos inhalatorios; con esto, las dos mujeres que sí los tienen, se constituyen en las más ancianas del grupo de tumbas individuales. En las tumbas múltiples hay mujeres aún mayores, pero en estos casos el complejo inhalatorio está asociado con el varón.

La presencia del niño de dos años en la tumba 44 es una incógnita, ya que evidentemente a esa edad no se puede ser practicante de chamanismo; no obstante, el equipo inhalatorio que se le asocia es uno de los de mayor calidad artística. El motivo de la tableta con el camélido grabado aparece en otras representaciones de San Pedro de Atacama, pero el tubo que la acompaña ( $\left.\mathrm{n}^{\circ} 1873\right)$ es único y escapa estilísticamente a toda comparación, por lo que pensamos que debe ser foráneo. Es interesante agregar que el pequeño varón (suponemos que es de sexo masculino por la presencia de arco) fue enfardado utilizando ganchos de atalaje para las amarras, cosa que se repite sólo en cuatro tumbas más de Solcor 3. Según nuestras indagaciones, esta manera de hacer los fardos funerarios es puneña, lo que, sumado al tubo y, por qué no, a la propia tableta, hablaría en favor de una situación atípica e intrusiva en Solcor 3. 
En general, los datos antropofísicos apuntan a que los chamanes de Solcor 3 no difieren biológicamente de la población del mismo sitio. La distancia genética señalada por los rasgos de variación discontinua no da resultados significativos, como para pensar que el origen genético de los portadores sea diferente del de los no portadores. Lo mismo ocurre en relación a la deformación craneana intencional, cuyo análisis estadístico muestra que no hay diferencias notorias, ni en los tipos ni en las frecuencias deformatorias de los portadores y no portadores. En conclusión, podemos decir que los chamanes son individuos que surgen de la misma población biológica local y que además manifiestan identidad étnica con ese mismo grupo.

La diversidad de formas y de estilos en las tabletas $\mathrm{y}$ en los tubos hace pensar en una probable diversidad de origen de estos objetos. Hay tabletas y tubos exclusivos en sus detalles, y únicos, no sólo en Solcor 3, sino también en el contexto general de San Pedro de Atacama. Entre las más evidentes cabe mencionar las tabletas $\mathrm{n}^{\text {os }} 1023$, $1045,1112,1265,1573,1909,2117,2518$, y entre los tubos los ${ }^{\text {os }} 1113,1873,2768,8431,8446$. Frente a los estandarizados patrones estéticos de la alfarería, de los tejidos y de la cestería, que pareciera enmarcar un esquema etno-icónico muy definido para los atacameños, la diversidad observada en los implementos para alucinógenos se manifiesta contrastante e, incluso, incoherente. Dentro de este contexto se esperaría una mayor uniformidad entre las tabletas y entre los tubos, o al menos no una disparidad tan marcada.

Si las frecuencias pudieran señalar lo autóctono, diríamos que en la Fase A las tabletas que con mayor probabilidad pudieron haber sido confeccionadas en San Pedro de Atacama son las de cajas rectangulares con un personaje antropomorfo sobre el borde; entonces, la pieza $\mathrm{n}^{\circ} 1573$, en la que el recipiente representa el tronco, y la cabeza y los pies se ubican en los extremos opuestos, podría considerarse como un patrón foráneo. Lo mismo puede decirse de aquella tableta ( $\left.n^{\circ} 1909\right)$ en que la superficie del panel se sitúa en un plano más bajo que el borde del recipiente, siendo que la generalidad presenta las dos partes al mismo nivel. En la Fase B, donde la tendencia es hacia formas trapezoidales o hiperbólicas, no se esperaría encontrar formas elípticas como la tableta $n^{\circ} 1023$; o, donde la tendencia es de paneles planos o grabados, no concuerda la presencia de apéndices no figurativos, como en el ejemplar $n^{\circ} 2518$.
No creemos que, en una sociedad fuertemente tradicionalista en relación a su acervo artístico, las innovaciones individuales pudieran llegar a alterar tan drásticamente los modelos consuetudinarios; mucho menos en lo que se refiere a objetos y representaciones rituales, para los cuales sabemos que las exigencias y el conservantismo son más estrictos, por estar imbuidos de prejuicios sobrenaturales que no pueden ser alterados caprichosamente. A primera vista podemos decir que en Solcor 3, casi 1/4 de las tabletas es foráneo, proporción que podría aumentar cuando se estudie este problema con más profundidad. Lamentablemente, la información disponible sobre las tabletas transandinas es ínfima y no permite disponer de referencias para confirmar el carácter alóctono de muchas tabletas de San Pedro de Atacama y, mucho menos, dirimir sus lugares de origen.

Se ha detectado una cierta relación entre objetos psicotrópicos y la presencia de elementos foráneos (Llagostera et al. 1988). En Solcor 3 hay tres de 10 tumbas con alfarería foránea que tienen objetos inhalatorios, lo que equivale a un 30\%. En un recuento de 22 cementerios de San Pedro de Atacama se ha obtenido el mismo porcentaje promedio señalado para Solcor 3, y en cuanto a tumbas con cerámica local y objetos psicotrópicos, el porcentaje baja a $18 \%$. La alta coincidencia de parafernalia inhalatoria con elementos foráneos asociados en las mismas tumbas está, sin duda, señalando una relación de los chamanes con las redes de tráfico, en las que no es improbable que también se hayan integrado las propias tabletas. Lo importante es constatar que en torno a los chamanes, va convergiendo una serie de situaciones que en sumatoria, los van configurando como personajes peculiares dentro del contexto sociopolítico: capaces de manejar el mundo natural y sobrenatural, poseedores de emblemas de poder o estatus (hachas), y ahora, relacionados con el tráfico caravanero.

Como conclusión, estamos en condiciones de señalar que los individuos que en Solcor 3 han sido encontrados en sus tumbas, asociados con objetos para inhalar alucinógenos, presentan varios atributos culturales similares a los del resto de la población, pero otros, que los hacen diferir de los patrones comunes. Las distancias genéticas señalan para ellos, una raigambre compartida con la población local, y la deformación craneana, tomada como indicador étnico, confirmaría su filiación a la comunidad atacameña. Estos dos últimos registros señalan que los portadores de implementos psicotrópicos son 
miembros de la población local que, por determinados méritos o designios, han adquirido la condición de chamanes. Es notoria la frecuencia con que los chamanes aparecen asociados con el tráfico caravanero transandino, con evidencia de un moderado estatus y también con símbolos de poder. Los antecedentes etnográficos sudamericanos nos sugieren que los individuos que conjugaban las condiciones enumeradas habrían sido los que sustentaban el mando entre los atacameños. En consecuencia, el chamanismo parecería constituir prerrequisito para configurar las jefaturas en San Pedro de Atacama, con mayor notoriedad, en el período de más intensa influencia altiplánica.

\section{ANEXO \\ Las tumbas de los portadores de objetos psicotrópicos}

A continuación se describirán los contextos antropofísicos y ergológicos de las tumbas de Solcor 3, en las que se encontraron objetos representativos del complejo inhalatorio. No se trata de dar un registro exhaustivo de los ajuares funerarios, sino de relevar lo más atingente a nuestra problemática. En ciertos casos no ha sido posible diagnosticar el sexo, la edad y/o la deformación craneana de algunos restos humanos debido al mal estado de conservación, o porque el cuerpo se encuentra aún dentro del fardo funerario. Para facilitar la descripción de la cerámica hemos recurrido a las formas que Tarragó (1976) asigna con números romanos, siempre y cuando las formas analizadas coincidan con las definidas por esta investigadora. Por último, agrupamos las tumbas de acuerdo a las fases que hemos establecido; pero aquellas cuya afiliación no es segura, las hemos segregado en un tercer grupo. Las tabletas y tubos pueden ser ubicados en las láminas por su número de registro.

\section{Tumbas de la Fase A}

Tumba 6: Tumba múltiple que albergaba tres cuerpos: uno, masculino, de 25-30 años, con deformación fronto-occipital; otro, femenino, de 35-40 años, sin diagnóstico de deformación; y, el tercero, femenino, de 50-55 años y con deformación fronto-lambdoidal. Los objetos inhalatorios estaban sobre el omóplato izquierdo del varón y consisten en: una tableta $\left(n^{\circ} 1112\right)$ hiperbólica con un felino tridimensional sobre el panel, con incrustaciones de piedras azules y blancas representando los ojos y los dientes; un tubo de madera muy largo ( $\left.n^{\circ} 1113\right)$, con boquilla de conos superpuestos, diseños pirograbados y envoltura de piel; una cucharilla de hueso con figura de ave en un extremo y otra de madera sin decoración. El contexto funerario es muy numeroso y cabe destacar entre sus componentes: un arco (asociado al varón), capachos, cestería, calabazas, collares, una cuchara de madera, palitos con sustancia no identificada en un extremo, dos objetos de madera con tallados en relieve en una de sus caras (semejando sellos), conchas de caracol de agua dulce (Strophocheilus sp.), husos y ovillos de lana, una brocha de fibras vegetales y una caja tubular de caña. La cerámica corresponde al tipo Negro Pulido la que está representada por dos botellones de forma X, uno con decoración B en el cuello y el otro sin decoración; dos recipientes de forma IX y dos de forma VII.

Tumba 8: Un individuo femenino de 45-50 años, sin deformación craneana. El ajuar inhalatorio consiste sólo en un tubo de hueso. En el resto del contexto se registran tres canastos, un capacho y una brocha de fibras vegetales. La alfarería del tipo Negro Pulido está representada por un tiesto de forma VII y otro de forma IX.

Tumba 10: Un individuo masculino de 45-50 años, sin diagnóstico de deformación craneana. Una bolsa tejida, conteniendo el complejo inhalatorio, estaba depositada al lado derecho del cuerpo. En el interior de la bolsa se encontraba una tableta rectangular ( $\mathrm{n}^{\circ}$ 1188), cuyo panel está decorado con puntuaciones, un tubo simple de madera y posiblemente otro de caña, una cucharilla de hueso con grabado geométrico, y dos bolsitas de cuero. Además, una bolsa de tejido fino con probables semillas de vilca (Anadenanthera sp.). Entre los objetos del resto del ajuar cabe mencionar tres cestos, un capacho y una cuchara de madera. Dos cerámicas tipo Negro Pulido, una de forma $\mathrm{X}$ con decoración en el cuello de tipo B, y otra, de forma VII.

Tumba 24: Un individuo del sexo masculino, 40-45 años de edad y sin deformación craneana. El único objeto seguro del complejo psicotrópico es una 
tableta rectangular $\left(n^{\circ} 1573\right)$ que representa un ser humano con la cabeza sobresaliendo de un extremo del recipiente, y los pies, del otro extremo; podría considerarse también como parte del equipo inhalatorio, una cucharilla de hueso con motivo estrellado en la parte superior. Destacan entre otros objetos: un arco y astiles de flechas, un hacha con hoja lítica, cuentas de collar y pendientes romboidales, una caja de madera y dos de caña, un capacho y dos cestos. Todo el ajuar cerámico es del tipo Negro Pulido y consiste en un botellón de forma X con decoración $\mathrm{B}$ en el cuello, dos tiestos de forma VII, uno de ellos más grande y más amplio, y uno en forma de mediaesfera achatada con asas-apéndices en el labio.

Tumba 27: Tumba múltiple de tres cuerpos: un individuo del sexo masculino de 30-35 años, otro, del sexo femenino de 45-50 años, ambos sin deformación craneana; un tercer cuerpo reducido a un conjunto de huesos fracturados que se encontró debajo del cuerpo masculino. Asociado al varón, se encontró una tableta de forma hiperbólica ( $\left.n^{\circ} 3038\right)$, sin decoración. También se asocian con este individuo, un arco y una flecha, una maza, una caja de hueso y otra de madera, dos instrumentos de hueso y husos para hilar; con la mujer, tres cestos y una calabaza; además de éstos, hay otros objetos que se podrían asociar a cualquiera de los tres cuerpos. $\mathrm{La}$ alfarería estaba junto a la mujer y consiste en dos tiestos Negros Pulidos de forma VII.

Tumba 29: Un individuo del sexo masculino de 30-35 años, sin deformación del cráneo. En el equipo para alucinógenos se registra una tableta rectangular $\left(\mathrm{n}^{\circ} 1668\right)$ con una figura humana en volumen sobre el borde, con orejas rectangulares y largos brazos, un tubo de hueso y semillas probablemente de vilca (Anadenantera sp.). Se contabilizan entre otros componentes del ajuar, un arco, una maza y cestería. Dos tiestos tipo Negro Pulido, uno fragmentado, de forma IX, y otro, entero, de forma VII.

Tumba 47: Tumba triple compuesta por un adulto de sexo masculino, de 30-35 años y sin deformación craneana; además, dos niños de tres años, no diagnosticables en cuanto a sexo y deformación craneana. El individuo adulto es el portador del equipo psicotrópico, ya que lo lleva junto al brazo izquierdo: una tableta hiperbólica ( $\mathrm{n}^{\circ}$ 1909) con el panel corto y más bajo que el borde del recipiente, un tubo de hueso y una cucharilla también de hueso. Como otros objetos del contexto general podemos señalar: un arco y flechas, un hacha con hoja lítica, cuentas de colar, un pilón de madera con figura antropomorfa, una caja de caña y otra de madera, una calabaza, un capacho y cestería. Cerámica del tipo Negro Pulido representada por un botellón forma X con un medallón al pastillaje en el cuello, que lleva dos excavaciones que representan los ojos y tres para la boca, y dos piezas con forma VII.

Tumba 52: Un cuerpo del sexo masculino, 30-35 años, sin deformación craneana. Se registran los siguientes objetos del complejo alucinógeno: una tableta rectangular $\left(n^{\circ} 2046\right)$ con figura antropomorfa con orejas recortadas y largos brazos, un tubo de hueso, bolsitas de cuero, tres piedras discoidales pulidas, un pilón de piedra con representación antropo-zoomorfa, una cucharilla de hueso, y una caja de madera. El resto del ajuar funerario consta, entre otros, de: un arco y flechas, un hacha con hoja lítica, un cincel con hoja de bronce, cuentas de collar, un capacho y tres cestos. La cerámica se clasifica dentro del tipo Negro Pulido, con un botellón forma X y decoración $\mathrm{B}$, una forma IX y una VII; además, un pequeño tiesto globular achatado de base plana.

Tumba 56: Presenta un cuerpo no alterado, y huesos disturbados correspondientes a 11 individuos. El cuerpo in situ es de un individuo de 19 años, cuyo sexo y deformación craneana no han sido posibles determinar. Entre los otros restos se identifican dos hombres de 40-45 y 45-50 años, con deformaciones fronto-lambdoidal y fronto occipital, respectivamente; dos mujeres de 25-30 y 35-40 años, sin deformación la primera y con deformación fronto-lambdoidal la segunda; además, un adulto sin diagnóstico, tres niños y tres recién nacidos. Entre el ajuar disturbado se encontró una tableta rectangular $\left(\mathrm{n}^{\circ} 2207\right)$ con figura de felino en relieve con la cabeza hacia el recipiente, y un fragmento de cucharilla de madera. Destacan entre otros componentes del alterado contexto de esta tumba: fragmentos de arco y astiles de flechas, un hacha, una cuchara de madera, cuentas de collar, adornos de cobre, tablillas con múltiples excavaciones, cajas de hueso y de madera, calabazas, capachos y cestería. La cerámica es Negra Pulida con dos botellones de forma $\mathrm{X}$ y decoración $\mathrm{B}$ en el cuello, dos tiestos de forma VII y dos formas similares a la IX, pero con paredes rectas y labios evertidos; una lleva las asas-apéndices en el labio y la otra, a la mitad de la pieza.

Tumba 62: Contiene cuatro cuerpos disturbados: uno, del sexo masculino de 15-20 años sin deformación craneana; otro, del sexo femenino de 35-40 años y con 
deformación fronto-occipital; un tercero, de un niño de 11 años, y el cuarto, un feto. Por la alteración de la tumba, el complejo psicotrópico no es asignable a ninguno de los cuatro individuos; como objetos más seguros de este complejo vamos a considerar: una tableta rectangular $\left(\mathrm{n}^{\circ} 2381\right)$ con figura humana en volumen, que tiene las manos a la espalda, un tubo de hueso, y una cucharilla de madera. Entre otros objetos de la tumba podemos enumerar: un arco y flechas, un recipiente de madera, una caja de caña y cestería. El contexto alfarero está representado por un botellón forma X, con medallón facial al pastillaje en el cuello, dos piezas forma VII, ambas con medallones faciales a medio cuerpo, y una pieza troncocónica invertida alargada; todas las piezas, muy fragmentadas, son del tipo Negro Pulido.

Tumba 116: Un individuo del sexo masculino de 35-40 años, sin deformación craneana. Próximo al hombro izquierdo se encontró una bolsa que contenía una tableta rectangular $\left(n^{\circ} 13141\right)$, sin decoración sobre el panel, un tubo de caña, una cucharita de hueso y otra de madera, un morterito, un pilón de madera, y un recipiente esférico de madera. Otros componentes del ajuar son: un arco y flechas, una brocha de fibra vegetal, una cuchara de madera y cuatro cestos. La cerámica es del tipo Negro Pulido y presenta las siguientes formas: un botellón forma $\mathrm{X}$ con decoración $\mathrm{B}$, tres vasijas de forma VII, dos de forma IX y una similar a la forma IX, pero de boca más abierta.

\section{Tumbas de la Fase B}

Tumba 1: Un individuo femenino de 45-50 años, sin deformación craneana intencional. Porta una tableta rectangular $\left(\mathrm{n}^{\mathrm{o}}\right.$ 0958) de panel planiforme sin decoración, con una perforación circular que lo atraviesa de un lado al otro, y un tubo de hueso $\left(n^{\circ} 0959\right)$ grabado con motivos en zigzag. Destacan entre otras pertenencias, una cuchara de madera, una calabaza piriforme, cestos, ovillo de lana y agujas de espinas de cactáceas. El ajuar alfarero está compuesto por dos tiestos restringidos ovoides (el menor con asas-apéndices verticales) y uno similar a la forma IX; todos corresponden al tipo Gris Grueso Pulido y presentan labios engrosados y evertidos.

Tumba 2: Un adulto sin diagnóstico biológico, que podría corresponder a sexo masculino por su asociación con arco, y un niño recién nacido. Como único objeto inhalatorio se registra un tubo sencillo que se encontraba envuelto en un tejido policromo.
En el ajuar general se distinguen: un arco y flechas, una brocha de fibras vegetales, cuentas de collar, dos recipientes de calabazas, un caracol de agua dulce (Strophocheilus sp.), un capacho y dos cestos. Tenía tres piezas cerámicas Gris Gruesas Pulidas, una ovoide y dos hemisféricas de boca levemente cerrada; además, una vasija también hemisférica pero de color café-rojizo. Para esta tumba se registra una fecha de 680 \pm 90 DC (Beta-27191).

Tumba 3: Un individuo masculino de 15-20 años, sin diagnóstico de deformación. El ajuar inhalatorio, que se ubica al lado izquierdo del cuerpo, consiste en una tableta $\left(n^{\circ}\right.$ 1023) con recipiente elipsoidal, alargado y un reducido panel ovoide aplanado, un tubo ( $\mathrm{n}^{\circ}$ 1025) de madera y una bolsa de cuero. Entre otros objetos se registran: un arco y flechas, un hacha con hoja de madera, una tablilla con múltiples excavaciones, varillas de madera, un cincel con hoja de bronce, y cestería. Un tiesto restringido ovoide tipo Gris Grueso Pulido, de labios engrosados y evertidos.

Tumba 5: Un individuo masculino de 35-40 años, sin deformación craneana. El ajuar inhalatorio está integrado por: una tableta hiperbólica $\left(\mathrm{n}^{\circ} 1075\right)$ decorada en bajorrelieve con la figura de un camélido coronado, que lleva un bulto sobre la espalda, un tubo de madera ( $\mathrm{n}^{\circ}$ 1076) que lleva esculpido un felino en la parte central y una cabeza de camélido en el extremo distal, una cucharilla de madera sin decoración, y otra de hueso, grabada, que en su forma general representa un ofidio; además, dos bolsitas de cuero. En el numeroso ajuar resaltan: un arco y astiles de flechas, un mango de hacha, una caja cilíndrica de madera y una cuchara del mismo material, una tablilla excavada, varillas, un palillo con cara antropomorfa en un extremo, un cincel con hoja de bronce y cestería. Cinco piezas componen el contexto cerámico: un tiesto similar a la forma IX; dos tiestos troncocónicos invertidos de base hemisférica; un tiesto similar a los precedentes, de paredes más evertidas, base plana, con una mitad roja y la otra negra; por último, un plato bastante hondo. Algunas de estas piezas resaltan por el notorio grosor de las paredes y, a excepción de la bícroma, se clasifican como Gris Grueso Pulido. Para esta tumba se dispone de una fecha TL de 920 120 DC (UCTL-48).

Tumba 12: Un individuo masculino de 20-25 años, sin deformación artificial del cráneo. El complejo de objetos psicotrópicos está compuesto por una tableta 
hiperbólica ( $\left.\mathrm{n}^{\circ} 1265\right)$ con muescas en las esquinas superiores del panel y una decoración geométrica y, además, con cavidades donde seguramente hubo incrustaciones de piedras; un tubo de caña, una cucharilla cilíndrica de madera y, posiblemente, bolsitas de cuero. Otros objetos del contexto son: dos cajas cilíndricas de caña y otra de madera, un arco y astiles de flechas, dos hachas de madera, una placa de metal, y cinco cestos. La alfarería está representada por: tres piezas Gris Gruesas Pulidas, restringidas; una campaniforme de color rojo que presenta conjuntos de líneas negras paralelas, rectas o en zigzag, dispuestas verticalmente (alfarería foránea); y un pequeño tiesto esferoidal.

Tumba 16: Tumba de tres individuos: uno de sexo masculino de 25-30 años, sin deformación craneana y dos de sexo femenino, uno de 25-30 años y el otro de 20-25 años; las dos mujeres presentan deformación fronto-occipital. La mujer de 25-30 años es prácticamente un fardo de huesos alterados, sólo con una concha de ostión (Argopecten purpuratus) como ajuar. No está claro a cuál de los otros dos individuos pertenecen los objetos inhalatorios, representados por una tableta $\left(n^{\circ} 1425\right)$ cuyos lados mayores son levemente convexos y los extremos muy convexos, una cucharilla de madera y una bolsita de cuero. Con el hombre hay un arco y flechas, un hacha, un capacho, cestería y 10 pequeños objetos de cobre similares a campanitas de cuatro puntas. Para la mujer sólo se registra un cesto directamente asociado. Entre otros objetos no asignables a ninguno de los tres cuerpos tenemos: una cuchara de madera, con figura de felino tallado en el mango y conchas de caracoles de agua dulce (Strophocheilus sp.). La cerámica de esta tumba corresponde al tipo Gris Grueso Pulido con tres formas ovoides, una similar a la forma VII, una media esfera, un plato, un troncocono con la parte inferior redondeada, base plana y grabado (asociado al varón), y una especie de cucharón de cerámica.

Tumba 20: Se trata de dos tumbas muy próximas, a tal punto que, al enterrar el cuerpo más tardío, se alteró al que ya estaba ahí ubicado. El equipo para alucinógenos pertenece al último que fue inhumado; se trata de un individuo del sexo masculino de 25-30 años, sin deformación craneana. El equipo inhalatorio se componía de una tableta hiperbólica $\left(n^{\circ} 1479\right)$ sin decoración, un tubo de caña con boquilla de madera y saquitos de cuero. Cabe enumerar algunos de los otros objetos del ajuar funerario, como: un arco y flechas, una caja tubular de hueso y otra de caña, dos cajas de madera, tres cucharillas de huesos, tres cestos (entre los que destaca uno, por su forma de troncocono invertido y un reborde anular en la base) y una cuchara de mango esculpido. Sólo se registra una pieza cerámica de forma troncocónica invertida, base plana y decoración tiwanakota (foránea).

Tumba 55: Un individuo masculino de 30-35 años y deformación fronto-occipital. El conjunto de implementos para alucinógenos se compone de una tableta rectangular $\left(\mathrm{n}^{\circ} 2117\right)$ con dos apéndices antropomorfos, un tubo de madera, tres cucharillas grabadas (dos de hueso y una de madera), dos palillos, gravilla de oxidado de cobre y espinas de cactáceas. Entre otros elementos del contexto funerario cabe destacar: un posible fragmento de arco y astiles de flechas, un hacha con hoja de bronce, una tablilla con múltiples excavaciones y palillos, un punzón con punta de bronce, cuentas de collar, una cuchara de madera, una brocha de fibras vegetales, una calabaza, un capacho y cestería. El contexto ceramológico lo constituyen dos tiestos ovoides y uno similar a la forma IX pero de paredes más rectas: los tres, del tipo Gris Grueso Pulido.

Tumba 69: Se trata de una tumba doble: un individuo de sexo masculino de 35-40 años, con deformación fronto-lambdoidal y otro, de sexo femenino de 40-45 años y sin deformación craneana. Los elementos para inhalación de alucinógenos se encontraban asociados al varón y comprenden: una tableta hiperbólica $\left(n^{\circ} 2491\right)$ que lleva grabada en el panel una figura de perfil genuflexa mirando hacia arriba, un tubo de caña con boquilla de madera y una bolsita de cuero. El arco y las flechas están directamente junto al varón, pero el resto del ajuar parece estar compartido por ambos cuerpos. Destacan una cuchara de madera, cuentas de collar, husos, una concha de caracol de agua dulce (Strophocheilus sp.), un capacho y cinco canastos. Dos piezas cerámicas integran el ajuar funerario, siendo ambas - una vasija esferoidal y un plato hondo- del tipo Gris Grueso Pulido.

Tumba 78: Hay un cuerpo sin alterar que corresponde a un individuo del sexo masculino de 35-40 años, con deformación fronto-occipital; tres cuerpos más, disturbados, uno masculino de 40-45 años, sin deformación, otro femenino de 30-35 años, con deformación fronto-lambdoidal, y un niño de seis meses. El ajuar inhalatorio se asocia con el hombre no alterado y consiste en una tableta hiperbólica ( $\left.\mathrm{n}^{\circ} 2725\right)$ sin decoración, dos tubos de caña, una cucharilla de madera, y dos bolsitas de 
cuero. Asociados a este mismo cuerpo se encontró un arco y flechas, un hacha con hoja de piedra, una tablilla con múltiples excavaciones y palillos y, una caja de hueso con espinas en su interior. En el resto del ajuar, sin asignación segura, tenemos: un arco, un hacha (esta vez con hoja de hueso) y otra tableta excavada; además, una cuchara y una espátula de madera, una brocha de fibras vegetales, dos conchas de caracoles (Strophocheilus sp. y Oliva peruviana), cuentas de collar, torteras, una calabaza, un capacho, y nueve cestos. La cerámica es del tipo Gris Grueso Pulido y se representa en cuatro piezas: una vasija ovoide, un plato hondo, un tiesto esferoidal grabado y un tiesto similar a la forma IX pero de paredes más rectas.

Tumba 79: Se trata de un enterratorio doble compuesto de un individuo de sexo masculino de 35-40 años, sin deformación craneana, y otro de sexo femenino de 30-35 años, con deformación fronto-lambdoidal. La parafernalia psicotrópica se encontró asociada con el varón y consistía en una tableta rectangular $\left(\mathrm{n}^{\circ} 2764\right)$ con cinco largos apéndices en el lugar del panel (uno quebrado antiguamente), un tubo inhalatorio $\left(n^{\circ} 2768\right)$ con un sacrificador antropomorfo de prominente nariz tallado en el centro y una bolsa de cuero. Al parecer, la mayor cantidad de ajuar está dispuesto en relación al varón: un arco y flechas, un hacha con mango grabado y hoja de piedra, una tablilla multiexcavada y varillas, dos cinceles con hoja de bronce. Otros elementos del ajuar compartido, o pertenecientes a la mujer, son: una brocha de fibras vegetales, un peine, un palillo de madera y una cuchara, ambos con figura antropomorfa, tres conchas de caracol (Strophocheilus sp.), un capacho, husos, calabazas y cestería. La cerámica está representada por una vasija ovoide del tipo Gris Grueso Pulido y dos recipientes de forma tronco cónica invertida, gruesos, mitad negro y mitad rojo.

Tumba 99: Dos individuos que no ha sido posible diagnosticar. El complejo para alucinógenos está compuesto por una tableta hiperbólica $\left(\mathrm{n}^{\circ} 3722\right)$ que en el panel lleva un personaje en vista frontal con un gran tocado y los brazos sobre el pecho, un tubo de madera ( $\left.{ }^{\circ} 3724\right)$ con un sacrificador que representa un camélido antropomorfo tallado en la parte central y una cabeza de camélido en el extremo distal, una cucharilla de madera con figura de ave en un extremo, y una bolsita de cuero. Destacan en el resto del ajuar una cuchara, un mortero y un pilón de madera, una tablilla con excavaciones múltiples $\mathrm{y}$ varillas, un cincel con hoja de bronce, cuentas de collar y tres cestos. La alfarería es de tipo Gris Grueso, y está representada por una vasija esferoide de cuello pronunciado y otra hemisférica con asascintas horizontales.

Tumba 101: Un individuo sexo masculino de 30-35 años sin diagnóstico de deformación craneana. El ajuar inhalatorio se compone de una tableta trapezoidal $\left(n^{\circ} 3741\right)$ con los bordes mayores convexos, sin decoración en el panel, una boquilla de madera para tubo inhalador, y dos cucharillas de madera, una de ellas con un ave tallada en un extremo. Del contexto funerario resaltan un arco, una cuchara de madera, una caja de caña, cuentas de collar y un cesto. Como representante ceramológico tenemos una vasija esferoidal Gris Gruesa de cuello pronunciado.

Tumba 103: Un individuo sexo masculino de 25-30 años, con deformación frontolambdoidal. Como parte de los elementos psicotrópicos sólo se registra un tubo de madera ( $n^{\circ} 3766$ ) con figura antropomorfa central de estilo Tiwanaku y una cabeza de camélido en el extremo distal. Entre otros integrantes del ajuar funerario tenemos un arco, una cuchara de madera, un gancho de atalaje, cuentas de collar y dos cestos. La cerámica está presente por una vasija esferoidal de tipo Gris Grueso y un fragmento de tiesto tronco cónico invertido, posiblemente bicolor.

Tumba 107: Un cuerpo sin diagnosticar, pero por la presencia de arco y hacha podría asumirse que se trata de un varón. El ajuar inhalatorio se encontraba dentro de una bolsa tejida, la que a su vez se hallaba envuelta por una faja policroma; los objetos contenidos en este paquete son: una tableta hiperbólica $\left(n^{\circ} 8432\right)$ con figura genuflexa de perfil, realizada en bajorrelieve y calados, y ataviada con incrustaciones de piedra, un tubo $\left(\mathrm{n}^{\circ}\right.$ 8431) con decoración grabada y cubierto con láminas de aleación de oro, una cucharilla de madera, y una bolsita de cuero. Esta tumba presenta un voluminoso ajuar dentro del cual se destacan un arco, un hacha, un pilón y dos cucharas de madera, una tablilla multiexcavada y varillas, 19 objetos de cobre en forma de campanitas de cuatro puntas, y 10 cestos. La alfarería de tipo Gris Grueso se hace presente con tres vasijas ovoidales. Además, como pieza foránea, se encontró un vaso troncocónico invertido de color rojo con diseños en negro; tiene un asa-cinta vertical que lleva adherida la figura de un cuadrúpedo.

Tumba 112: Un cuerpo sin diagnosticar; por su asociación con arco y hacha habría que suponer que 
se trata de un varón. Es el único caso en Solcor 3 en que un individuo porta dos bolsas tejidas, cada una con parafernalia completa para inhalar. Una bolsa contenía una tableta rectangular ( $\left.\mathrm{n}^{\circ} 8438\right)$ de lados mayores convexos e incrustaciones de cobre en el panel, un tubo de madera $\left(\mathrm{n}^{\circ} 8439\right)$ con figura de lagarto al centro y cabeza de camélido en su extremo distal, una cucharilla de madera, tres bolsitas de cuero, y gravilla de oxidado de cobre. La otra bolsa llevaba en su interior una caja de caña, una bolsita de cuero con gravilla de oxidado de cobre y una bolsa aterciopelada, donde estaba el segundo equipo inhalatorio. Este último equipo consistía en una tableta hiperbólica $\left(\mathrm{n}^{\circ}\right.$ 8445) sin decoración en el panel, un tubo de madera sencillo, una cucharilla de madera, dos bolsitas de cuero, y un fino tubito de caña con embarrilado en un extremo. En el resto del ajuar funerario se distinguen: un arco y flechas, un hacha, una cuchara y tres canastos. Como ajuar alfarero tenía dos vasijas ovoides Gris Gruesas y fragmento de plato.

Tumba 117: Consta de un individuo de sexo masculino de 30-35 años, sin deformación, y de un niño de 10 años; además, hay otro niño de dos años que fue disturbado con anterioridad. Como objetos inhalatorios se cuentan una tableta hiperbólica ( $\left.{ }^{\circ} 13166\right)$ que lleva grabado en el panel una figura de perfil y flectada, y un tubo $\left(n^{\circ} 13167\right)$ con figura antropomorfa central y cabeza de camélido en un extremo. Entre otros componentes del ajuar funerario se registran: un arco y flechas, un hacha con hoja de hueso, dos cucharas, cuentas de collar y cestería. La cerámica contempla una vasija ovoidal con cuello pronunciado y otra de paredes rectas, base cóncava y pequeñas asas-cintas horizontales; ambas piezas son del tipo Gris Grueso. Para esta tumba se dispone de una fecha $\mathrm{C}^{14}$ de 480 \pm 80 DC (Beta-27192).

\section{Tumbas de afiliación insegura}

Tumba 4: Un individuo masculino de 50-55 años, sin deformación craneana. El conjunto psicotrópico estaba dentro de una bolsa policroma tejida, que se ubicaba al lado izquierdo del cráneo y consistía de una tableta hiperbólica $\left(n^{\circ} 1045\right)$ que lleva en el panel un sencillo felino, un tubo de madera y una cucharilla también de madera. Destacan, además, un arco y flechas, cestería y cuentas de collar. Carece de alfarería.

Tumba 44: Contiene el cuerpo de un niño de dos años; por la edad del individuo no se puede determinar el sexo por diagnóstico directo, pero por la presencia de arco, podemos asumir que se trata de un varón. Como objetos psicotrópicos se le depositaron una tableta hiperbólica ( $\mathrm{n}^{\circ}$ 1874) con un camélido grabado en su panel, un tubo de madera $\left(n^{\circ} 1873\right)$ con felino tallado al centro y cabeza de camélido en el extremo distal, y una bolsita de cuero. Entre otros componentes del ajuar funerario pueden enumerarse: un arco y flechas, cuentas de collar, calabazas, cestería y ganchos de atalaje. No tiene alfarería.

Tumba 49: Contiene dos cuerpos infantiles no diagnosticados biológicamente; por la ausencia de arco en el ajuar funerario hay posibilidades de que se trate de mujeres. Uno de ellos tenía a la altura del hombro derecho una bolsa tejida conteniendo una tableta rectangular ( $\mathrm{n}^{\mathbf{0}}$ 3058) bastante tosca, un tubo de caña, y gravilla de oxidado de cobre. Entre los otros objetos acompañantes de los cuerpos se registraron: una cuchara de madera, varillas del mismo material, tres recipientes de calabazas y tres cestos. No hay alfarería.

Tumba 50: Un individuo masculino de 40-50 años, con deformación frontolambdoidal, acompañado de un niño de 18 meses. Junto a la pelvis izquierda del adulto de ubicó el paquete psicotrópico que contenía: una tableta rectangular $\left(n^{\circ} 1989\right)$ con figura antropomorfa en volumen, portando una cabeza en la mano izquierda y un objeto indeterminado en la derecha; un tubo de madera $\left(\mathrm{n}^{\circ} 1990\right)$ con la figura de un cóndor tallada en el centro y una cabeza de camélido en el extremo, y un mango de cucharilla. Entre el resto del ajuar de esta tumba destacan: un arco y flechas, un hacha con hoja de cobre, una cuchara de madera, un cincel con hoja de bronce, una tablilla multiexcavada y varillas de madera, una caja de madera y una de caña, cuentas de collar, dos recipientes de calabazas y cestería. El ajuar ceramológico es bastante atípico, ya que presenta formas del Negro Pulido y formas que podrían asimilarse al Gris Grueso Pulido. Hay un botellón forma $\mathrm{X}$ con asas en el cuerpo y sin decoración; dos troncoconos invertidos de base cóncava (uno de ellos grabado); dos tronco conos de color rojo con base anillada, ambos grabados y con trazados en pintura negra; un tiesto similar a la forma IX pero en color natural de la arcilla; por último, un tiesto Negro Pulido de forma II. Esta última pieza alfarera parece intrusiva dentro del contexto, ya que por su tipo correspondería a una fase (o subfase) anterior a las que estamos considerando; a esto, habría que añadir que se la encontró totalmente fragmentada, 
mientras que las otras piezas están completas. Para esta tumba se dispone de una fecha TL de $720 \pm 95$ DC (UCTL-51).

Tumba 65: Esta tumba aloja el cuerpo de un individuo de sexo masculino de 40-45 años y sin deformación craneana; además, otro cuerpo disturbado de un adulto cuyo sexo y edad no han sido diagnosticados. Los implementos inhalatorios se ubicaron dentro de una bolsa policroma tejida, a la altura del hombro derecho, y consisten en: un tubo de caña, con boquilla de madera, una cucharilla de hueso, una cajita de caña, dos bolsitas de cuero y gravilla de mineral de cobre. Otros materiales que se pueden asignar con seguridad al mismo cuerpo son un arco y flechas, y una tablilla multiexcavada. En el contexto alfarero se registran: un tiesto ovoide del tipo Gris Grueso Pulido, uno troncocónico invertido de base anillada, con una mitad negra y la otra roja; además, cinco tiestos Negros Pulidos troncocónicos invertidos altos. De la asociación cerámica y de sus tipos se desprende que se trata de dos entierros diacrónicos; los dos primeros tiestos se asocian al cuerpo intacto y lo asimilan a la Fase B, y los cinco últimos corresponden al cuerpo que fue alterado al depositar el anterior, correspondiendo a la Fase A.

Tumba 70: Es una tumba disturbada en la que se encontraron restos de ocho individuos: uno de sexo masculino de 50-55 años, con deformación frontal; dos mujeres, una de 55-60 años y otra de 40-45, ambas sin deformación craneana; dos adultos sin diagnóstico, dos niños de siete años y uno de tres. De todos ellos, sólo los de mayor edad parecen haber sido encontrados in situ. Los objetos inhalatorios no pueden asignarse a ningún cuerpo en especial, y están representados por una tableta de recipiente trapezoidal $\left(n^{\circ} 2518\right)$ con dos apéndices en el lugar del panel, un tubo de madera y restos de una bolsita de cuero. En el confuso ajuar funerario resaltan: un arco, un pilón de madera, una tablilla multiexcavada y palillos, husos, cuentas de collar, un capacho y cestería. La alfarería se compone de un botellón de forma X y decoración B en el cuello, un puco hemisférico de labio levemente evertido; ambas piezas son del tipo Negro Pulido. También se hacen presentes en el contexto cerámico, tres piezas ovoides negras y gruesas, y una forma similar a la IX de paredes más rectas y con las misma características de las precedentes. Esta mezcla de atributos entre las piezas cerámicas nos hace pensar en una tumba de transición entre la Fase A y la Fase B.
Tumba 76: Esta tumba está compuesta por ocho cuerpos, algunos disturbados y otros no. Un individuo de sexo masculino de 45-50 años y con deformación frontolambdoidal; dos mujeres de $35-40$ y $30-35$ años, y una tercera, adulta sin diagnóstico de edad; para ninguna de las tres fue posible determinar el tipo de deformación craneana; por último, dos niños de 12 y dos años y otro, de 6-12 meses. Entre los componentes psicotrópicos consideramos una tableta hiperbólica ( $\mathrm{n}^{\circ}$ 2648) con panel no decorado, un tubo de madera $\left(n^{\circ} 2647\right)$ con figura antropomorfa central y cabeza de camélido en el extremo distal, un tubo de hueso, una cucharilla de madera con figura de ave tallada en el extremo, dos cajas de caña, y una bolsita de cuero. Entre otros objetos de los ajuares destacan un arco, un hacha con hoja de hueso, un pequeño mortero de madera, cuentas de collar, una concha de caracol (Strophocheilus sp.), calabazas y cestería. El componente cerámico está conformado por mezcla de tipos Negro Pulido, Gris Grueso y formas atípicas. Tipo Negro Pulido: un vaso cilíndrico alto, un vaso troncocónico invertido bajo, un puco hemis-férico achatado, dos tiestos de forma VII y uno de forma IX pequeño, con una minúscula asa vertical labio-adherida. Tipo Gris Grueso Pulido: dos piezas ovoides de cuello levemente pronunciado y dos troncocónicos de base hemisférica (uno pequeño). Formas atípicas: un pequeño vaso hemisférico tosco, un tiesto similar a la forma IX con asas-apéndice en el labio y de color café-rojizo, y un pequeño recipiente de doble compartimiento, comprimido lateralmente. Al parecer, la alfarería Gris Gruesa, así como los objetos del complejo alucinógeno estarían asociados con el individuo de sexo masculino que ocupaba esta tumba. En consecuencia, este último correspondería a la Fase B y los otros cuerpos podrían pertenecer a la Fase A.

Tumba 92: Tumba con tres cuerpos disturbados: un individuo de sexo masculino de 40-45 años, y una mujer de 55-60 años, ambos sin deformación craneana, y un niño de seis meses. Como objetos del complejo inhalatorio podemos considerar un tubo de madera, una cucharilla de hueso cuya forma y decoración grabada imitan un ofidio, y una bolsita de cuero. Entre el resto del confuso ajuar funerario se cuentan: un hacha con hoja de bronce, un pilón de madera, espinas de cactus, cuentas de collar, un capacho, dos conchas de caracoles (Strophocheilus sp.), calabazas y ocho cestos. El contexto alfarero presenta una vasija ovoidal del tipo Gris Grueso y un tiesto subcilíndrico bajo de base hemisférica, el que técnicamente se podría asimilar con el tipo 
Negro Pulido. La tumba podría interpretarse como enterratorios diacrónicos de la Fase A y la Fase B, pero lo atípico del último ceramio podría hablar también en favor de una tumba de transición.

Tumba 97: Está compuesta por cinco cuerpos: un individuo de sexo femenino 30-35 años, con deformación frontolambdoidal, otro individuo sin diagnóstico de sexo, pero que por la presencia de arco en la tumba podría tratarse de varón; su edad se estima en 15-20 años y no fue posible determinar si tiene o no deformación craneana. A estos cuerpos hay que agregar tres niños de 5 años, 18-24 meses y 0-6 meses de edad. Los objetos inhalatorios están representados por una tableta rectangular ( $\left.n^{\circ} 3679\right)$, tan burda que más bien podría tratarse de una preforma, un tubo de madera, una cucharilla de madera también en proceso de trabajo, y una bolsita de cuero. Entre otros componentes del ajuar funerario se registran: un arco, una cuchara de madera, cuentas de collar, una calabaza y tres cestos. Esta tumba no presenta alfarería.

Tumba 106: Un cuerpo no diagnosticado. Dentro de una bolsa policroma se encontró un tubo inhalatorio de madera, dos cucharillas de madera, una de ellas con diseños en zigzag, y una bolsita de cuero; en la misma bolsa tejida había un recipiente de hueso y una espátula del mismo material. El resto del ajuar estaba compuesto por una cuchara de madera y cuatro cestos. La alfarería está ausente.

Tumba 114: Un cuerpo sin diagnosticar, al parecer masculino, por la presencia de arco y hacha. Sólo un tubo de madera como seguro objeto inhalador; también podría hacer parte del complejo, una cucharilla de hueso grabada. Otros componentes del contexto funerario son: un arco, un hacha, una cuchara de madera, cuentas de collar y dos cestos. No hay cerámica.

\section{REFERENCIAS CITADAS}

AMBROSETTI, J., 1899. Notas de arqueología, Calchaquí. Buenos Aires, Argentina.

1907-08 Exploraciones arqueológicas en la ciudad prehistórica de La Paya. Facultad de Filosofía y Letras, Publicaciones de la Sección de Antropología 3, Buenos Aires.

ANSCOMBE, F. J., 1948. The transformation of poisson binomial and negative binomial data. Biometrika 35: 246-254.

BARON, A. M., 1984. Cráneos atacameños y su asociación con tabletas para alucinógenos. Simposio Culturas Atacameñas. XLIV Congreso Internacional de Americanistas. Universidad del Norte, Instituto de Investigaciones Arqueológicas, San Pedro de Atacama.

BASS, W., 1971. Human osteology: A laboratory and field manual of the human skeleton. Spedal Publications, Missouri Archaeological Society, Columbia.

BERENGUER, J., A. DEZA, A. ROMAN y A. LLAGOSTERA 1986. La secuencia de Myriam Tarragó para San Pedro de Atacama: Un test por termoluminiscencia. Revista Chilena de Antropología 5.

BIRD, J., 1943. Excavations in Northern Chile. Anthropological Papers of the American Museum of Natural History XXXVIII, parte IV, Nueva York.

1948. Preceramic cultures in Chicama and Viru. En $A$ reappraisal of Peruvian archaeology, W. C. Bennett (Ed.). Memoirs of the Society for American Archaeology 4: 21-28. Menasha.
BRAVO, L. y A. LLAGOSTERA 1986. Solcor 3: Un aporte al conocimiento de la Cultura San Pedro. Período 500 a 900 DC. Chungara 16-17: 323-332.

BROOKS, S., 1955. Skeletal age at death: The reliability of cranial and pubic age indicators. American Journal of Physical Anthropology 13: 567-597.

CASTRO, M. y S. QUEVEDO, 1984. Proposiciones metodológicas para el estudio de los rasgos no-métricos en el cráneo humano. Boletín del Museo Nacional de Historia Natural 40: $173-210$.

CONKLIN, W., 1986. The mythic geometry of the Ancient Southern Sierra. En The Junius Bird Conference on Andean Textile, A. P. Rowe (Ed.). The Textile Museum, Washington D. C.

CORDY-COLLINS, A., 1979. Cotton and the Staff God: Analysis of an ancient Chavin textile. En The Junius Bird Pre-Columbian Textile Conference, A. P. Rowe y L. Schaffer (Eds.), pp. 51-60, The Textile Museum y Dumbarton Oaks, Washington D. C.

DROESSLER, J., 1981. Craniometry and biological distance. Center for American Archaeology, Northwestern University, Evanston.

ELIADE, M., 1976. El chamanismo y las técnicas arcaicas del éxtasis. Fondo de Cultura Económica, México D. F.

ENGEL, F., 1963. A preceramic settlement in the Central Coast of Perú: Asia, Unit 1. Transactions of the American Philosophical Society 53, parte 3, Filadelfia. 
FRIKEL, P., 1961. Mori-a festa do rapé. Indios Kachúyana, Rio Trombetas. Boletim do Musen Paraense Emilio Goeldi, Antropología, nova serie (julio) 12: 10-34.

GILBERT, B. y T. McKERN 1973. A method for aging the female os pubis. American Journal of Physical Anthropology 38: 31-38.

GONZALEZ, A. R., 1974. Arte, estructura y arqueología, análisis de figuras duales y anatrópicas del Noroeste Argentino. Ediciones Nueva Visión. Buenos Aires.

HALIFAX, J., 1982. Shaman, the wounded healer. The Crossroad Publishing Company, Nueva York.

LATCHAM, R., 1938. Arqueología de la región atacameña. Prensas de la Universidad de Chile, Santiago.

LEHMANN-NITSCHE, R., 1902. Catálogo de las antigüedades de la Provincia de Jujuy. Talleres de Publicaciones del Museo de la Plata, Buenos Aires.

LE PAIGE, G., 1963. La antigüedad de una tumba comprobada por carbono 14 y el ambiente que la rodea. Revista Universitaria. Anales de la Academia Chilena de Ciencias Naturales XLVIII (26): 167-176.

_ 1964 El precerámico en la cordillera atacameña y los cementerios del Período Agroalfarero de San Pedro de Atacama. Anales de la Universidad del Norte 3, Antofagasta.

_ 1965. San Pedro de Atacama y su zona. Anales de la Universidad del Norte 4, Antofagasta.

LOOSER, G., 1926. Las tabletas para tomar rapé del Museo Nacional. Revista Chilena de Historia Natural XXX: 19-22.

LOVEJOY, C. O., R. S. MEINDL, T. R. PRYZBECK y R. P. MENSFORTH. 1985. Chronological metamorphosis of the auricular surface of the Ilium: A new method for the determination of adult skeletal age at death. American Journal of Physical Anthropology 68: 15-28.

LlagosterA, A., M. A. COSTA y F. TELleZ, 1988 Ms. Interrelaciones transandinas en la formación y consolidación de la Cultura San Pedro. Informe de Proyecto FONDECYT 1016/86, San Pedro de Atacama.

MCKERN, T. y T. D. STEWARD, 1957. Skeletal age changes in young American males, analyzed from the standpoint of identiftcation. Technical Report EP-45. Headquarters Quartermaster Research and Development Command, Natick, Massachusetts.

MEINDL, R. S. y C. O. LOVEJOY 1985. Ectocranial suture closure: a revised method for the determination of skeletal age at death based on the lateral-anterior sutures. American Journal of Physical Anthropology 68: 57-66.

MEINDL, R. S., C. O. LOVEJOY, R. P. MENSFORTH y R. A. WALKER, 1985. A revised method of age determination using the os pubis, with a review and tests of accuracy of other current methods of pubic symphysial aging. American Journal of Physical Anthropology 68: 29-45.

METRAUX, A., 1944. Estudios de etnografía chaquense. Anales del Instituto de Etnografía Americana V: 263-312.

- Ms s/f. Tribus de las laderas orientales de los Andes bolivianos.

MONTELL, G., 1926. An archaeological collection from the rio Loa valley, Atacama. Oslo Etnografiske Museum Skrifter, Bind 5, Hefte 1, Oslo.

NUÑEZ, L., 1963. Problemas en torno a la tableta de rapé. Anales de la Universidad del Norte 2: 149-168, Antofagasta.

OYARZUN, A., 1931. Las tabletas y los tubos para preparar y aspirar la paricá en Atacama. Revista Chilena de Historia y Geografía LXVIII (enero-marzo) (72): 68-76.

POSNANSKY, A., 1945. Tiahuanacu, the craddle of American man. J. J. Augustin Publisher, Nueva York.

REICHEL-DOLMATOFF, G., 1978. El chaman y el jaguar. Estudio de las drogas narcóticas entre los indios de Colombia. Siglo Veintiuno Editores, México, D. F.

ROSEN, E. VON, 1924. Popular account of archaeological research during the Swedish Chaco-Cordillera Expedition, 1901-1902. Alb. Bonniers Boktrykeri, Estocolmo.

ROWE, J. H., 1971. The influence of Chavin on later art styles. En Dumbarton Oaks Conference on Chavin, E. Benson (Ed.), pp. 101-124, Dumbarton Oaks, Washington, D. C.

SANGHVI, L. D. Comparison of genetical and morphological methods for a study of biological differences. American Journal of Physical Anthropology 11: 385-404.

TARRAGO, M., 1968. Secuencias culturales de la etapa agroalfarera de San Pedro de Atacama (Chile). XXXVII Congreso Internacional de Americanistas, vol. 2, pp. 119144. Buenos Aires.

1976. Alfarería típica de San Pedro de Atacama (norte de Chile). Estudios Atacameños 4: 37-73.

TELLO, J. C., 1923. Wira Cocha. Inca I (1): 93-320.

THOMAS, C. y M. A. BENAVENTE, 1984. Reflexiones metodológicas acerca de las creencias en la Cultura San Pedro a través del análisis de correspondencia de las tabletas de rapé. Simposio Culturas Atacameñas, Instituto de Investigaciones Arqueológicas R. P. G. Le Paige, San Pedro de Atacama.

THOMAS, C., M. A. BENAVENTE y C. MASSONE, 1985. Algunos efectos de Tiwanaku en la cultura de San Pedro de Atacama. Diálogo Andino 4.

TODD, T. W., 1920. Age changes in the pubic bone, I: The male white pubis. American Journal of Physical Anthropology 3: 285-334. 
TORRES, M. C., 1986. Iconografía de las tabletas para inhalar sustancias psicoactivas de la zona de San Pedro de Atacama, norte de Chile. Estudios Atacameños 7: 178-196.

— 1987. The iconography of South American snuff trays and related paraphernalia. Etnologiska Studier 37, Museo Etnográfico de Gotemburgo.

UBELAKER, D. H., 1978. Human skeletal remains: Excavation, analysis, interpretation. Aldine Publishing Company, Chicago.

UHLE, M., 1898. A snuffing tube from Tiahuanaco. Bulletin of the Museum of Science and Art I (4), University of Pennsylvania, Filadelfia.

1912. Las relaciones prehistóricas entre el Perú y la Argentina. Actas del XVII Congreso Internacional de Americanistas (1910), pp. 509-540. Buenos Aires.

1913. Tabletas de madera de Chiu Chiu. Revista Chilena de Historia y Geografía, año V, XVI (12): 454-458.
— 1915. Los tubos y las tabletas de rapé en Chile. Revista Chilena de Historia y Geografía, año V, XVI (20): 114-136.

URTON, G., 1981. At the crossroasds of the Earth and the sky. An Andean cosmology. University of Texas Press, Austin.

WASSEN, S. H., 1967. Anthropological survey of the use of South American snuffs. En Ethnopharmacologic search for psychoactive drugs, D. H. Efron et al. (Eds.), pp. 233-289. Public Health Service Publication 1645, Washington D. C.

1972. A medicine-man's implements and plants in a Tiahuanacoid tomb in highland Bolivia. Etnologiska Studier 32: 7-114.

YACOVLEFF, E. y F. L. HERRERA, 1935. El mundo vegetal de los antiguos peruanos. Revista del Museo Nacional III (1-2): 243-322. 